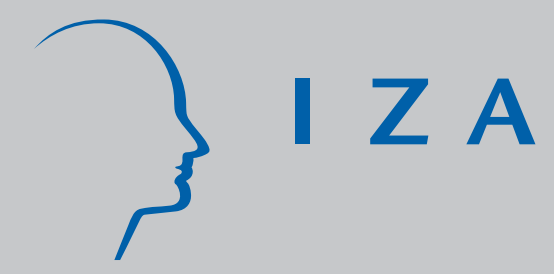

IZADP No. 3929

Child Welfare and Old-Age Security in Female Headed Households in Tanzania

Holger Seebens

J anuary 2009 


\title{
Child Welfare and Old-Age Security in Female Headed Households in Tanzania
}

\author{
Holger Seebens \\ University of Göttingen \\ and IZA \\ Discussion Paper No. 3929 \\ January 2009 \\ IZA \\ P.O. Box 7240 \\ 53072 Bonn \\ Germany \\ Phone: +49-228-3894-0 \\ Fax: +49-228-3894-180 \\ E-mail: iza@iza.org
}

Any opinions expressed here are those of the author(s) and not those of IZA. Research published in this series may include views on policy, but the institute itself takes no institutional policy positions.

The Institute for the Study of Labor (IZA) in Bonn is a local and virtual international research center and a place of communication between science, politics and business. IZA is an independent nonprofit organization supported by Deutsche Post World Net. The center is associated with the University of Bonn and offers a stimulating research environment through its international network, workshops and conferences, data service, project support, research visits and doctoral program. IZA engages in (i) original and internationally competitive research in all fields of labor economics, (ii) development of policy concepts, and (iii) dissemination of research results and concepts to the interested public.

IZA Discussion Papers often represent preliminary work and are circulated to encourage discussion. Citation of such a paper should account for its provisional character. A revised version may be available directly from the author. 


\section{ABSTRACT \\ Child Welfare and Old-Age Security in Female Headed Households in Tanzania*}

This paper is concerned with patterns of expenditure and child welfare among female headed $(\mathrm{FHH})$ and male headed households $(\mathrm{MHH})$ in Tanzania as well as with the underlying cause of potentially different patterns. I estimate semiparametric Engel curves to investigate household expenditure patterns while controlling for household characteristics and find that FHH spend significantly more money on the welfare of children and less on consumption of adult goods. In an attempt to explain this observed difference, I further investigate the empirical content of the old-age security hypothesis, which states that persons lacking the financial means to rely on themselves during old-age invest more in children who care for them in later periods. The results lend support to the idea that old-age security might be the driving force behind the observed differences of expenditure allocated towards the welfare of children. $\mathrm{FHH}$ having access to alternative means of old-age security, spend significantly less on child welfare. Furthermore, food expenditure levels of $\mathrm{FHH}$ and $\mathrm{MHH}$ with access to alternative old-age security become the same.

JEL Classification: D12, J12, J13, J14

Keywords: demand, female headed households, child welfare, old age security

Corresponding author:

Holger Seebens

Department für Agrarökonomie und Rurale Entwicklung

Platz der Göttinger Sieben 5

D-37073 Göttingen

Germany

E-mail: hseebens@uni-goettingen.de

\footnotetext{
* This research was made possible through funding from the Robert Bosch foundation. I would like to thank Stephan Klasen, Michael Grimm, Amartya Sen, Alexander Stein, Pramila Krishnan, Arnab Basu and Sylvie Lambert for help and comments on this version.
} 


\section{Introduction}

This paper is concerned with patterns of expenditure and child welfare among male headed (MHH) and female headed households (FHH) in Tanzania. It is often argued that women do care more about children than men and thus such behavior should be reflected by household expenditure within MHH and FHH. ${ }^{1}$ I estimate Engel curves to investigate household expenditure patterns while controlling for household characteristics and find that FHH spend significantly more money on the welfare of children and less on consumption of adult goods. ${ }^{2}$ Welfare of children is defined here in a broad sense and measured by the response of household demand for food, child clothing and education to changes in household demographic composition. Alcohol and tobacco are treated as adult goods as they are assumed to be entirely consumed by adults. The study further explores the reasons for such different spending patterns. One explanation is offered by the old-age security hypothesis which states that persons lacking the financial means to rely on themselves during old-age invest more in children who care for them. Women might be more constrained in terms of financial resources, assets and access to financial institutions and therefore invest more in children. The analysis of the empirical content of the old-age security hypothesis yields interesting results, though not unambiguously supporting it.

The distribution of resources within households has received wide attention in the past which has been spurred with the works of Manser and Brown (1980), McElroy and Horney (1981), Chiappori (1992), and Browning and Chiappori (1998). In these models, individuals are assumed to form a household while retaining their own personal interests and bargain with other members to accomplish their goals. The control over resources, individual contribution to household welfare or social status which are associated with bargaining power define the extent to which an individual can affect household decision making. The more bargaining power, the more say an individual has. In response to these considerations, a number of empirical studies appeared which address the question of the impact of women's bargaining

\footnotetext{
${ }^{1}$ See Haddad (1999) for a summary and further references.

${ }^{2}$ I consider tobacco and alcohol as adult goods in line with foregoing studies that have demonstrated the demographic separability of these items. Demographic separability implies that increasing consumption of these items only leads to an income effect, but do not bring about substitution of expenditure from an adult good toward a child good as clothing for children (Deaton, Ruiz-Castillo and Thomas 1989).
} 
power on household decision making. These studies often find that the food share tends to increase with increasing status of women (see Quisumbing and Maluccio 2000, Haddad and Hoddinott 1994, Thomas 1990, Thomas 1993).

Extending this idea to the welfare of children, others have looked at the impact of women's bargaining position on the nutritional status of children or the household's expenditure on education (Thomas 1994, Thomas, Lavy and Strauss 1996, Thomas and Strauss 1992). The general result of these papers is that women seem to care more for children, which finds its expression in expenditure shares for child goods which rise with improvements of the status of women. The measurement of female status is however difficult and subject to discussion. The first problem relates to the operationalization of status. First, one may consider status in economic terms, that is, women who contribute substantial income to the household should be regarded as having more say in household decision making. But status may also be defined by cultural norms which assign women a particular role that determines their influence on decisions. Finally, personality affects the position women occupy within the household. While the latter two are difficult to measure, most studies rely on economic variables.

Individual contributions to household income may be expressed through cash income earned on the wage labor market, cash transfers which are tied to a person or simply assets which can be sold or used for the production of goods. This approach not only neglects the value of household work - which may be or may be not perceived as economically valuable by household members - but is also particularly troublesome in agrarian and subsistence dominated societies where wage labor is not wide spread or almost non-existent. Income based measures are furthermore subject to endogeneity problems, since the decision to work is a function of bargaining power. That is, individuals with a larger say-because of personality or other characteristics - may decide not to work at all. Personality is unobserved which why income as a measure of bargaining power is potentially correlated with the error term. A solution might be to use control over assets. However, the same problem arises from assets purchased during marriage which has led many authors to employ assets brought to marriage believed to be independent from current decision making and personality effects. Neverthless, all these measures are subject to measurement error and it remains unclear to what extent they really reflect true individual 
bargaining power.

In view of these difficulties, it is desirable to find other ways to isolate female and male influence on household decision making. One option is to compare $\mathrm{MHH}$ and $\mathrm{FHH}$ and to assume that headship reflects decision making power. This approach is not entirely free of problems. It assumes first that FHH are a homogeneous group which is not the case in Tanzania and many other sub-Saharan African countries. A FHH may arise out of widowhood or divorce whereas in other cases women are married but the husband has temporarily outmigrated. However, in those households where no male partner is currently present, men are unlikely to exert a major influence on how consumption expenditure is to be used and how much money is allocated to it. ${ }^{3}$ Although the estimates might be slightly biased due to the identification problem of the true household decision maker, it should still be possible to estimate average effects and to investigate these for systematic differences between FHH and MHH.

A common approach to compare expenditure patterns of $\mathrm{FHH}$ and $\mathrm{MHH}$ is to introduce a dummy variable representing the sex of the household head. This approach assumes a linear. that is, parallel scaling of the demand curves in response to the household head's sex. The results presented here show that this assumption does not hold for some goods. Furthermore, by applying the dummy variable approach it is not possible to investigate different responses of expenditure behavior to an additional child in different age and sex groups as well as the impact of the household head's education and sex. The approach followed here is to estimate Engel curves separately for each household category and to compare the parameters and the resulting curves in order to trace different expenditure patterns.

\section{The old-age security motive for investing in chil- dren}

The evidence to date on FHH spending and its impact on child welfare is mixed. Some studies using African data demonstrate a positive impact of female headship on child welfare (Bruce 1989, Kennedy and Peters 1992). Handa $(1994,1996)$ repeats this result for the case of Jamaica while Rogers (1996) finds that among MHH and FHH in The Dominican Republic, there

\footnotetext{
${ }^{3}$ This may not be true regarding productive investments.
} 
are no substantial differences in the level of food demand while controlling for household characteristics and food prices. However, children in FHH at the lowest range of income on the other hand tend to be better nourished compared to $\mathrm{MHH}$.

The empirical studies yet largely do not attempt to explain this empirical regularity. Many authors attribute the higher spending of FHH on child welfare to the fact that mothers are closer to their children through child care which is usually considered a women's task and thus renders women more aware of their children's well-being (Bruce 1989, Rogers 1996, Handa 1996). Haddad (1999) lists some further conjectures: (i) women may be driven by social and cultural norms to ensure an adequate share of food for children. (ii) Women spend more time with their children and thus have naturally a closer relation to them, which induces women to spend more on child welfare. (iii) Due to time constraints, women in FHH may also buy more processed food which is more expensive but easier to prepare. (iv) The general longer life expectancy of women and the risk of divorce and widowhood induces women to invest more in the health of their children. Women are also often married to older men, which further increases the risk of being widowed at early ages. In case of widowhood, poor women need help from their children to ensure survival.

The 'investment in children' argument for securing support from children during old ages bears resemblance to the old-age security hypothesis for fertility. The claim that couples use children as a risk coping strategy has found some empirical support by Cain $(1981,1983)$ and Nugent and Gillaspy (1983). In an early review of the old-age security motive of couples in developing countries to get children Nugent (1985) illustrates the different underlying conditions for which the motive may hold and outlines 8 different causes: (i) underdeveloped capital markets, (ii) uncertainty about the quantity of marketable goods and financial assets necessary as insurance for old age and disability, (iii) absent or inefficient private insurances or public insurance programs, (iv) loyalty of children to their parents, (v) absence of markets for labor that enable women to generate income outside the household, (vi) underdeveloped markets for goods and services that elderly people consume, (vii) absence of a young spouse, and finally (viii) the perception of the relative importance of old age.

The first three issues refer to the existence and functioning of capital 
and insurance markets. The fourth point refers to social norms that aim at ensuring respect and loyalty of children to their parents. In the past, such loyalty might have decreased due to migration and abating social control. However, parents, who complain about the lack of loyalty they receive from their children, may simply want to extract more services from them (Nugent 1985).

Labor market that would allow women to generate income in case of widowhood are often underdeveloped or not existing, particularly in rural areas of many developing countries. As the data from the Tanzanian Integrated Labor Force Survey (URT (2002)) show, only 4.0 percent of economically active women find wage employment as opposed to 9.8 percent of the working male population. The seventh point refers particularly to women, since it is common in Tanzania and other developing countries, too, that women are younger than their husbands. ${ }^{4}$ Older men on the other hand often receive support by their younger wives as has been noted by Cain (1982). Furthermore, and not specific to Tanzania, women suffer from precarious land rights, where widowhood does not ensure continuity of accessing the land previously cultivated (Yngstrom 2002).

The points made by Nugent and others may not be restricted to fertility but might also apply to investments in child quality. Where the likelihood to become a widow at early ages is large and where means of insurance are lacking, women have an incentive to invest in the wellbeing and education of their children to ensure their support during old age. When an individual has no means to save, then investment into the human capital of childrenthat is health and education of the children-increases the returns during old age. This may hold particularly in cases where women cannot re-marry or are too old to get further children. When replacing fertility with child quality - where quality refers to health and education - then child quality and savings should appear as substitutes if the old-age security hypothesis is correct. ${ }^{5}$ At the core of the test proposed here is the introduction of savings into the demand function for child goods and food. I focus here only on demand for food which can be regarded as a proxy for investment into child health and education which is the most direct translation of spending

\footnotetext{
${ }^{4}$ Barbieri and Hertrich (2005) find that more than 50 percent of the couples in Tanzania exhibit an age difference between 5 to 14 years while in 12 percent of the households the difference amounts to more than 15 years.

${ }^{5}$ This argument has also been put forward by Cigno (1993).
} 
on children into future human capital of children.

\section{The data}

Tanzania makes a good case for the comparison of $\mathrm{MHH}$ and $\mathrm{FHH}$ as the incidence of $\mathrm{FHH}$ is quite large. The data is taken from the Tanzanian Household Budget Survey 2000/01 which covers all 20 mainland regions. After cleaning the sample consists of 18,783 households out of which 4,737 households classify themselves as FHH which amounts to a share of 25.2 percent.

The expenditure items covered are food, education ${ }^{6}$ and child clothing as child goods and alcohol and tobacco as adult goods. The treatment of food as a child good is strictly speaking not correct as food is not entirely consumed by children. To account for that fact, I include in each equation the share of children of different ages and sexes in total household size. ${ }^{7}$ Household demographics are included in the demand equations as well and are captured by the log of total household size and by the share of individuals in different age and gender categories relative to household size. Summary statistics of the data are given in table 1. Food is the major expenditure item of Tanzanian households and amounts to more than 60 percent for both household categories. The averages do not differ substantially between household categories; the expenditure shares for food in FHH are on average 3 percentage points higher compared to MHH. FHH spend also more on education and child clothing as reflected by the statistics, but again the means do not differ to a large extent. Expenditure on alcohol is very low which is partly due to low prices for alcohol. Tobacco expenditures are higher but do not exceed 5 percent on average. For both adult good categories, the shares are lower among FHH.

FHH tend to be smaller and as to be expected exhibit a low share of male adults and a high share of female adults. Otherwise, the household demographic composition does not reveal significant differences between household categories. Education of the head of household is included to approximate different types of work as it can be assumed that farmers and

\footnotetext{
${ }^{6}$ It should be noted that the data was collected before the abandonment of school fees for primary schools was implemented in 2003.

${ }^{7}$ As Rogers (1996) has shown, child nutrition increases at a faster rate with increasing food in $\mathrm{FHH}$.
} 
workers have different food needs compared to white collar workers. Furthermore, education may imply different preferences to certain goods. It is notable that the average educational level of the head of household in FHH is substantially below the level of MHH. Only 39 percent of female heads are primary educated and less than 10 percent have achieved secondary education. The availability of land is also lower in FHH compared to MHH as well as the number of existing savings accounts. The reported averages need to be interpreted in the light of lower expenditure propensities among FHH for adult goods. As shown in table 2, the number of FHH that purchase adult goods at all is smaller. Only 20 percent of FHH spend money on alcohol as opposed to 30 percent in MHH. Regarding tobacco, almost twice as much $\mathrm{MHH}$ purchase cigarettes or related products, while only 16 percent of $\mathrm{FHH}$ do so.

\section{Comparison of regression curves}

\subsection{Empirical approach}

To compare demand behavior across household categories, I begin with estimating for each household category $j$ and good $k$ separately a simple model of the form

$$
w_{i j k}=m\left(\ln \left(x_{i j}\right)\right)+\alpha z_{i j}+\beta d_{i j}+\varepsilon_{i j k}
$$

where $z_{i}$ is a vector of variables that capture the demographic profile of the $i$ th household of category $j{ }^{8} n$ is household size and $d$ denotes a set of regional dummy variables. ${ }^{9}$ Finally, the model includes controls for the 20 Tanzanian mainland regions ${ }^{10}$ as well as a dummy for rural households. The functional relationship between expenditure shares $w$ and the log of total expenditure per capita $\ln x$ is left unspecified which bears several advantages. First, this model is theoretically consistent as has been shown by Blundell, Duncan and Pendakur (1998) and exhibits all features of a well behaved demand function. Second, it has been found for the case of developing countries that models linear in the logarithm of total expenditure are not appropriate because Engel curves based on logarithmic expenditure are often

\footnotetext{
${ }^{8}$ For the sake of simplicity the household category index $j$ is dropped in the following.

${ }^{9}$ This model can be directly derived from an indirect utility function (see Pendakur 1999).

${ }^{10}$ Zansibar is not included in the HBS data.
} 
non-linear. In developing countries food Engel curves tend to be quadratic (see Bhalotra and Attfield 1998, Deaton and Paxson 1998). Even a quadratic form may be overly restrictive as it is plausible that with rising incomes, poor people substitute high quality food for lower quality food, which would cause the Engel curve to be flat or trending upwards at the lowest range of expenditures. The more income is available, the steeper the downward slope of the curve may get, while flattening out at the higher income ranges. Such a cubic trend is likely for countries exhibiting high levels of income inequality and severe poverty, although violating Gorman's (1981) rank three condition for exactly aggregable demand systems. ${ }^{11}$

The function $m(\cdot)$ and parameters $\alpha$ and $\beta$ are obtained by applying the partial linear model proposed by Robinson (1988) and Speckman (1988). Denoting $z=(z, d)$ and $\beta=(\alpha, \beta)$ one may write (1) in the general form

$$
w=m(x)+z \beta+u
$$

and obtain the parameter vector $\beta$ through

$$
\hat{\beta}=\left[(z-\hat{m}(z \mid x))^{\prime}(z-\hat{m}(z \mid x))\right]^{-1}\left[(z-\hat{m}(z \mid x))^{\prime}(y-\hat{m}(y \mid x))\right]
$$

where $m(z \mid x)$ denotes the nonparametric first moment of $z$ conditional on $x$. The standard errors of $\hat{\beta}$ are calculated using the sandwich estimator $\Psi^{-1} \Xi \Psi^{-1}$, where $\Psi=N^{-1} \sum_{i}\left(x_{i}-\hat{m}\left(z_{i} \mid x_{i}\right)\right)\left(x-\hat{m}\left(z_{i} \mid x_{i}\right)^{\prime}\right]$ and $\Xi=$ $N^{-1} \sum_{i}\left(x_{i}-\hat{m}\left(z_{i} \mid x_{i}\right)\right)\left(x_{i}-\hat{m}\left(z_{i} \mid x_{i}\right)^{\prime} \varepsilon_{i}^{2}\right.$. The nonparametric curve given by $m(x)$ can be recovered by regressing $w-z \beta$ on $x$.

The nonparametric part of the model is estimated using a weighted local polynomial regression (LOWESS) smoother which has been proposed by Cleveland (1979). Each point of the smoothed curve is calculated by

$$
m(x)=\sum_{i}^{N}\left(y_{i}-\alpha_{p}-\beta_{p}\left(x_{i}-x\right)\right)^{2} K\left(\frac{x_{i}-x}{h}\right)
$$

where (4) is minimized with respect to $\alpha_{p}$ and $\beta_{p}$. The function $K(\cdot)$ denotes a Kernel density with bandwidth $h$. The bandwidth is chosen via generalized

\footnotetext{
${ }^{11}$ Gorman (1981) has shown that any exactly aggregable demand system that satisfies utility maximization is at most of rank three, implying that a cubic term of the log of expenditure does not generate any additional informational gains.
} 
cross-validation which involves minimizing the criterion

$$
G C V=\frac{\sum \varepsilon^{2}}{\left(1-n^{-1} \operatorname{tr}(S)\right)}
$$

where $\varepsilon$ denotes the residuals obtained from (4) and $S$ is the smoothing matrix (Ruppert, Wand and Carroll 2003). Further, I provide estimates of the confidence intervals of the curves based on the smooth conditional moment (SCM) method suggested by Gozalo (1997). An advantage of this method as opposed to the wild bootstrap is that it is not only robust to heteroscedasticity, but also to violations of the normality assumption of the residuals. Although the LOWESS estimator exhibits better end effects as Nadaraya-Watson or Spline estimators it is not entirely immune to outliers in regions where data are sparse and hence the data have been trimmed by dropping the upper and lower $2.5 \%$ quantiles from the sample.

The estimation of the parameters using (1) is made difficult by two problems: (i) endogeneity bias due to the construction of the independent variable and (ii) endogeneity bias arising from the censoring of the dependent variable for all goods except food.

The theory of two-stage budgeting suggests that households divide the available budget into expenditure and savings and then decide on which goods to buy. Hence, total expenditure is a choice variable not exogenous to the consumer. Furthermore, the budget shares are calculated by dividing outlay for the $k$ th good by total expenditure. However, the measurement of household expenditure in developing countries is generally plagued by a number of difficulties like seasonal variation, recall errors, etc., which render expenditure data imprecise. Since the budget shares are constructed by dividing expenditure on the $k$ th good by total expenditure, the measurement error found in expenditure must translate into a measurement error of the budget share. Consequently, expenditure as an independent variable is correlated with the error term. Hausman (1978) has derived a regression based test for endogeneity. The same procedure can also be applied to account for inconsistency of the parameter estimates in the presence of endogeneity bias. The test as discussed in Hausman's paper is originally based on purely parametric methods but extends to and has found applications in the 
semiparametric framework as well. ${ }^{12}$ Consider the following model

$$
E\left(w_{i} \mid x_{i}, z_{i}\right)=m\left(x_{i}\right)+\beta z_{i}+u_{i}
$$

where $x$ is correlated with error term $u, m(\cdot)$ is again an undefined function and $z$ is a matrix containing variables which are assumed to be strictly exogenous. To conduct the test, assume that an instrumental variable $y$ highly correlated with $x$ but not correlated with $u$ is available and regress $x$ on $y$ as well as on the exogenous variables contained in $z$ and obtain $\nu$ given by the model

$$
E\left(x_{i} \mid y_{i}, z_{i}\right)=\lambda y_{i}+\gamma z_{i}+\nu_{i}
$$

Running regression (7) yields an estimate $\hat{\nu}_{i}$ which is introduced into (6)

$$
w_{i}=m\left(x_{i}\right)+\beta z_{i}+\delta \hat{\nu}_{i}+\varepsilon_{i}
$$

If $\delta$ turns out to be significantly different from zero, the null of no endogeneity bias present in the model must be rejected. Hausman demonstrates, that the inclusion of $\hat{\nu}$ is suited to yield consistent estimates of $\alpha$ and $\beta$ which in turn produce a consistent estimate of the nonparametric part of the model.

The problem of dealing with endogeneity of this form is the availability of instruments for expenditure. A frequently used variable is the log of total income per capita, which is just as problematic as total per capita consumption. Income fluctuates substantially in developing countries which leads many poor households to smooth consumption over time. High levels of income are therefore not indicative of high levels of expenditure. Furthermore, income is subject to even larger measurement problems as in the HBS it is recorded on the basis of a one year recall. The survey also contains a component that collects income data on a monthly basis, but given the seasonal fluctuation of income-which holds for agricultural income as well as for wage labor which is often not permanent-this only partially solves the problem. The problem to measure income accurately implies that income is a weak instrument for expenditure in the present setting. Weak instruments, however, lead to large standard errors of the instrumented variable rendering statistical inference difficult. Furthermore, if a weak instrument is even slightly correlated with the error term, then instrumental variable regression

\footnotetext{
${ }^{12}$ See Blundell et al. (1998) for an application.
} 
yields severely biased results which does not even disappear asymptotically (see Wooldridge (2002) for a discussion of this issue).

Expenditure, on the other hand, is much more stable over time and is recorded at a higher frequency and covers an entire month. ${ }^{13}$ The measurement error of consumption is therefore probably lower as compared to income. Given that the correlation between log of income per capita and $\log$ of expenditure per capita amounts to only 0.25 and that the impact of a weak instrument can be much more severe than the actual bias from not employing any instrument, the reported parameters in the tables are not corrected for endogeneity bias of this type as further suitable instruments are not available. When using income as an instrument for expenditure and including $\hat{\nu}$ in the set of equations, $\hat{\delta}$ turns out to be significant in most cases. However, the resulting estimates and the demand curves become unreasonable as the predicted expenditure shares are not anymore bounded between zero and one. Previous studies using income as an instrument for expenditure in a developed country context where data quality is much better demonstrate that the impact of endogeneity bias on the actual parameters is quite weak. However, the expected improvement of the quality of the estimates obtained here is likely to be low, even if suitable instruments were available (e.g., Blundell et al. 1998).

The second source of endogeneity bias arises from the censoring of the dependent variable for all non-food goods. To account for this problem, I adapt a two-stage estimation procedure of a generalized Tobit model for the semi-parametric framework (see for expositions of the approach for purely parametric models Amemiya 1985, Cragg 1971, Maddala 1983). ${ }^{14}$ First redefine (1) as a latent variable model of the form

$$
w_{i k}=\left\{\begin{array}{l}
m\left(x_{i}\right)+\alpha z_{i}+\beta d_{i}+\varepsilon_{i k} \quad \text { if } w_{i k}^{*}>0 \\
0 \quad \text { otherwise }
\end{array}\right.
$$

\footnotetext{
${ }^{13}$ Enumerators have visited the households at least 8 times over one month and collected data on consumption items.

${ }^{14}$ Two-step methods for censored models based on the inverse Mills ratio have been criticized for being inconsistent and not utilizing the full sample in the second (see Shonkwiler and Yen 1999). However, the alternative two-step method proposed by Shonkwiler and Yen exhibits inferior behavior compared to Heckman approaches when the extent of censoring exceeds 50 percent (Tauchmann 2005).
} 
The latent variable $w_{i k}^{*}$ is defined by

$$
w_{i k}^{*}=\gamma x_{i}+\alpha z_{i}+\beta d_{i}+\kappa_{i k}
$$

and determines whether the $j$ th good is chosen or not. That is, if $w_{i k}^{*}$ exceeds zero, the household decides to purchase the good. Unfortunately, $w_{i k}^{*}$ is unobserved but its sign can be recovered from whether the household buys the good or not. If the good is purchased, then $w_{i k}^{*}$ is positive and negative otherwise. Now assume that

$$
\left(\begin{array}{c}
\varepsilon_{i k} \\
\kappa_{i k}
\end{array}\right) \sim N\left[\left(\begin{array}{l}
0 \\
0
\end{array}\right),\left(\begin{array}{cc}
\sigma_{1}^{2} & \rho \sigma_{1} \\
\rho \sigma_{1} & 1
\end{array}\right)\right]
$$

Using $x \gamma$ for the parameters and independent variables involved in (10) along with the conditional first moment of a bivariate truncated normal distribution, yields the conditional expectation

$$
E\left(w_{i k} \mid w_{i k}>0\right)=m\left(x_{i}\right)+\alpha z_{i}+\beta d_{i}+\sigma \frac{\phi_{i}(x \gamma)}{\Phi_{i}(x \gamma)}
$$

where $\phi_{i}(\cdot)$ and $\Phi_{i}(\cdot)$ denote the standard normal density and distribution functions, respectively. This model can be estimated by applying Heckman's two-step approach (Heckman 1976), where initial parameters for $\gamma$ are estimated in a first stage probit model with

$$
\begin{array}{ll}
I_{i k}=1 & \text { if } w_{i k}>0 \\
I_{i k}=0 & \text { otherwise }
\end{array}
$$

as the dependent variable. Using the estimates $\hat{\gamma}$, the inverse Mills ratio $\hat{\phi}_{i} / \hat{\Phi}_{i}$ is constructed and substituted into (12), which can now be estimated using any consistent estimation procedure. Note, that the method explicitly allows the log of expenditure per capita to enter the first stage probit model parametrically instead of in a non-parametric form. ${ }^{15}$

The two-step procedure is subject to heteroscedasticity that can be accounted for either through the formula given in Heckman (1979) or by following the suggestion from Amemiya (1985) to estimate the variance-covariance

\footnotetext{
${ }^{15}$ Each probit equation has been tested for the inclusion of a squared term of expenditure per capita. The results of test are given along with the estimated parameters.
} 
matrix via $\Psi^{-1} \bar{\Xi} \Psi^{-1}$ which is the same as defined above, only that $\varepsilon_{i k}$ in $\bar{\Xi}$ is replaced by $\bar{\varepsilon}_{i k}=w_{i k}-\hat{m}\left(x_{i}\right)-\hat{\alpha} z_{i}-\hat{\beta} d_{i}-\hat{\sigma} \frac{\hat{\phi}_{i}}{\hat{\Phi}_{i}}$. In this study I follow the latter approach since it is easier to compute.

\subsubsection{Estimates of the Engel curves}

Figure 1 shows the food Engel curves for FHH and MHH, respectively. In all figures that follow, the dashed lines around the curves represent the 5 percent confidence intervals. Both curves have the expected downward slope and exhibit an approximately quadratic shape. There is a clear difference between the two curves indicating that food demand is systematically higher in $\mathrm{FHH}$ compared to $\mathrm{MHH}$ at the same levels of per capita expenditure. The difference amounts to about 6 percentage points at the lower ends of per capita expenditure, to 3 percentage points in the middle and to almost 10 percentage points at the upper consumption range. This difference is remarkable as poorer $\mathrm{FHH}$ focus on food more than $\mathrm{MHH}$ in either quality or quantity. Given the low price levels of basic food as maize and some vegetables in Tanzania a difference of 6 percentage points imply a substantial difference in food consumption among household members in FHH. ${ }^{16}$ A further observation worth noting is the fact that the MHH curve first increases until it reaches its saddle point at 10.84 of log expenditure per capita and starts to fall thereafter. The curve for FHH constantly exhibits a negative slope which suggests that among the poorest, FHH tend to assign greater importance to sufficient food supply compared to MHH. The curves further reveal no convergence but diverge with increasing expenditure. From an old-age security perspective, FHH therefore appear not to treat children as an investment good, as it may be assumed that savings and capital accumulation increase with rising expenditure levels.

The Engel curves for clothing and education are shown in figures 2 and 3. FHH spend more on child clothing, too. The curve for FHH remains above the MHH's curve across almost the whole range of expenditure. Differences are not substantial but may be overcompensated by better maintenance of child clothing within FHH. Demand for education exhibits the same path

\footnotetext{
${ }^{16}$ The mean price for maize grain, which is one of the major food crops and has the richest content of calories among the subsistence crops (on average 368 calories per 100 grams), cost 0.1 US dollar per kg. Sorghum grain which is also consumed in large quantities has similar prices and calorie contents (HBS 2000/01).
} 
Figure 1: Food budget shares for FHH and MHH

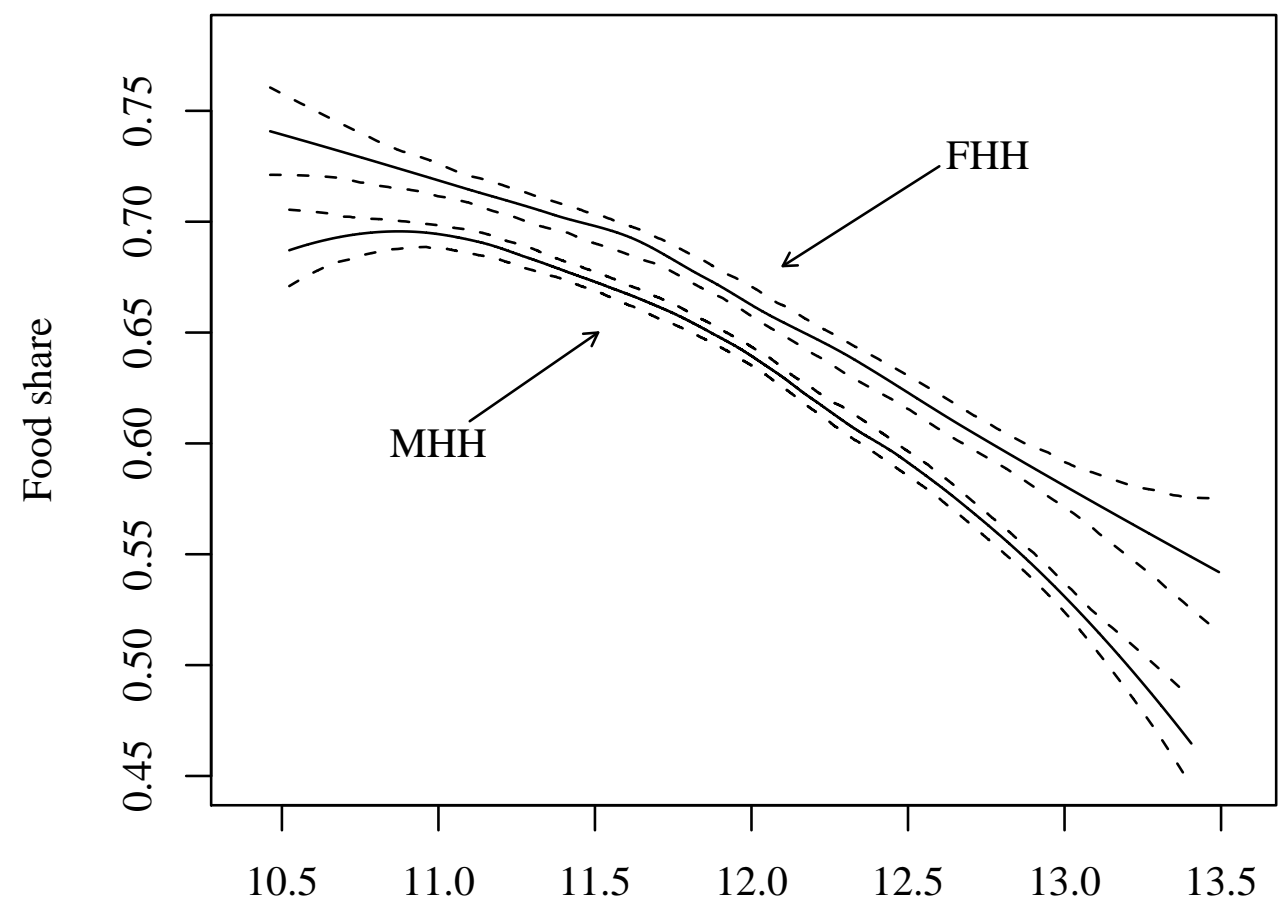

Log of total expenditure per capita

within both household categories at the lower end of expenditure but diverges slightly at the upper end.

The curves for the adult goods alcohol and tobacco exhibit substantially different shapes. While expenditure for alcohol is larger among FHH at lower ranges of expenditure the curves eventually cross. The FHH curve for alcohol is almost linear and is negatively sloped over the whole range of expenditure. Alcohol shares in $\mathrm{MHH}$ first fall but remain constant at 0.6 percent of total expenditure after crossing the FHH curve. Although FHH exhibit higher alcohol shares among poorer households, the overall budget share for alcoholic beverages does not even exceed 1 percent. However, prices for alcohol are low and consumption is often restricted to local brews as pombe, which can be produced very cheaply. Thus even small amounts of expenditure can imply substantial quantities of consumption. The curves need to be further interpreted in the light of the different consumption propensities 
Figure 2: Budget shares for clothing in $\mathrm{FHH}$ and MHH

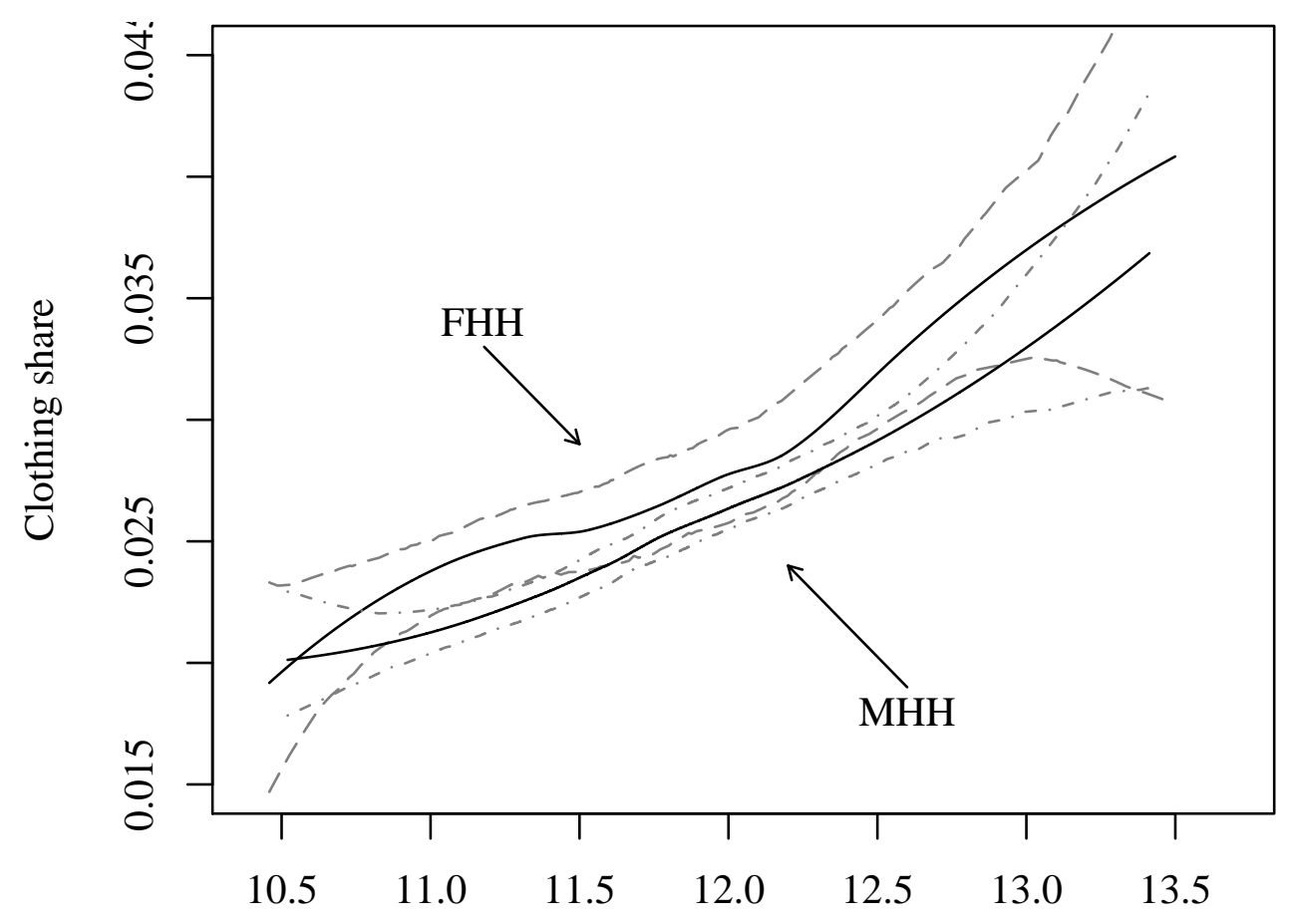

Log of total expenditure per capita

of alcohol among FHH and MHH whereas MHH exhibit a greater likelihood to consume alcohol consumption at all (see table 2). At the lowest range of expenditure, tobacco shares for FHH amount to 4.4 percent of the budget share while those for MHH start at 5.0 percent. Both curves exhibit on average a negative slope and remain distant from each other, though they do not appear to be parallel. ${ }^{17}$

The results for all different goods, although less clearly for education, visually establish systematically different patterns of demand for food and child goods as well as for the adult goods alcohol and tobacco. Whether this conclusion holds after statistical testing is investigated in the following section.

\footnotetext{
${ }^{17}$ As a first indication of significance of the distance between the curves one may use the confidence intervals which are given by the dashed lines around the two curves, although, as Härdle, Müller, Sperlich and Werwatz (2004) note, those confidence intervals should not be used for statistical testing of the difference of two curves.
} 
Figure 3: Budget shares for education in FHH and MHH

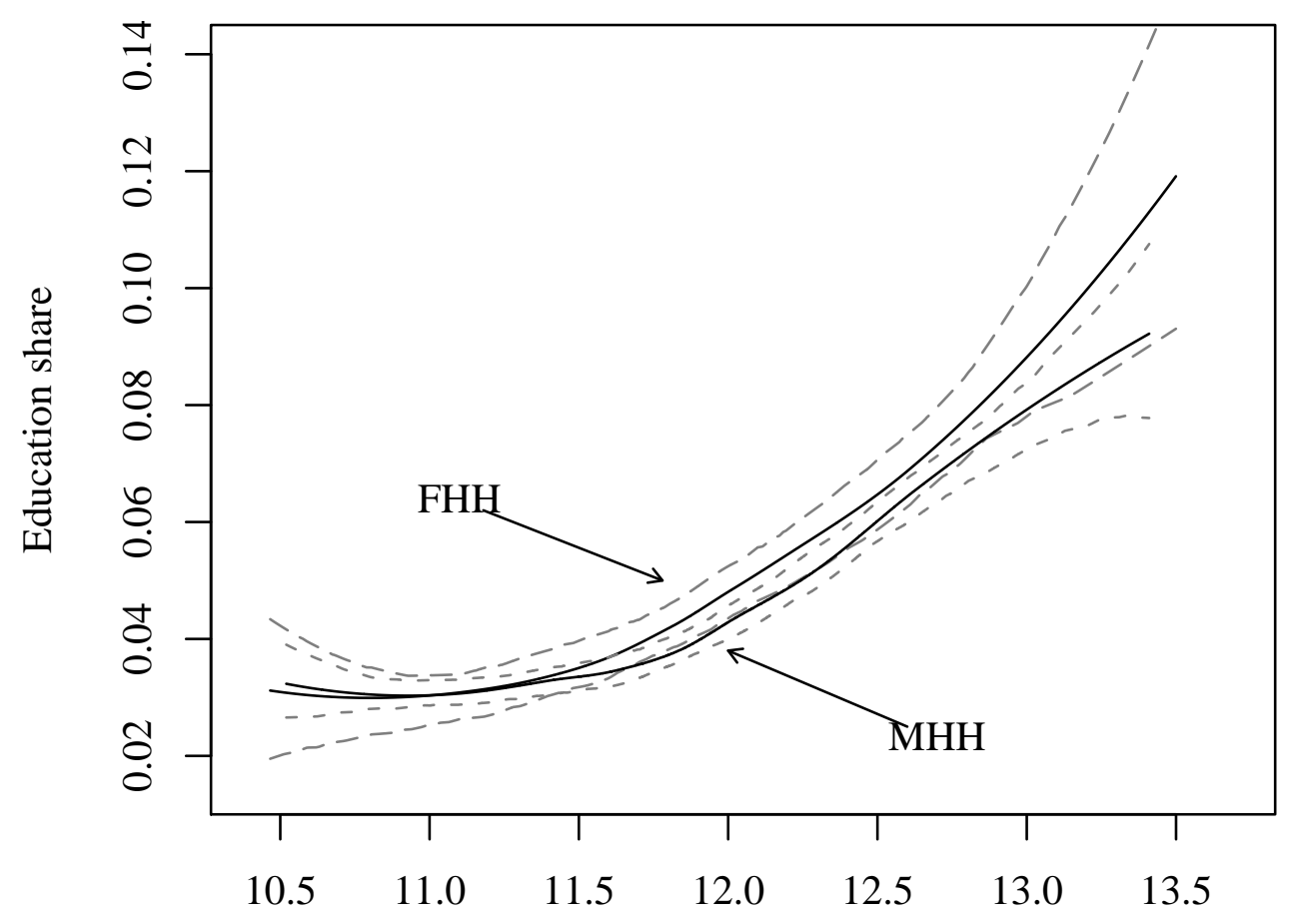

Log of total expenditure per capita

\subsubsection{Testing for shape equality}

Testing the equality of two regression curves is a common problem that is frequently addressed in the literature although most often for fixed design data. The fixed design refers to the case where the range of observations of the independent variable is the same for both curves. The Tanzanian household data is not conform to a fixed design, since the MHH and FHH data are treated here as two distinct populations with observations randomly distributed along the x-axis, and therefore do not match each other exactly.

The test pursued is based on the ideas of Härdle and Marron (1990) and Yatchew (1999) and (i) can handle random design data and (ii) allows for consecutive testing of two different hypotheses. The first hypothesis arises from the question whether the two curves are significantly distant from each other. To address this problem, one first seeks the set of parameters that 
Figure 4: Budget shares for alcohol in FHH and MHH

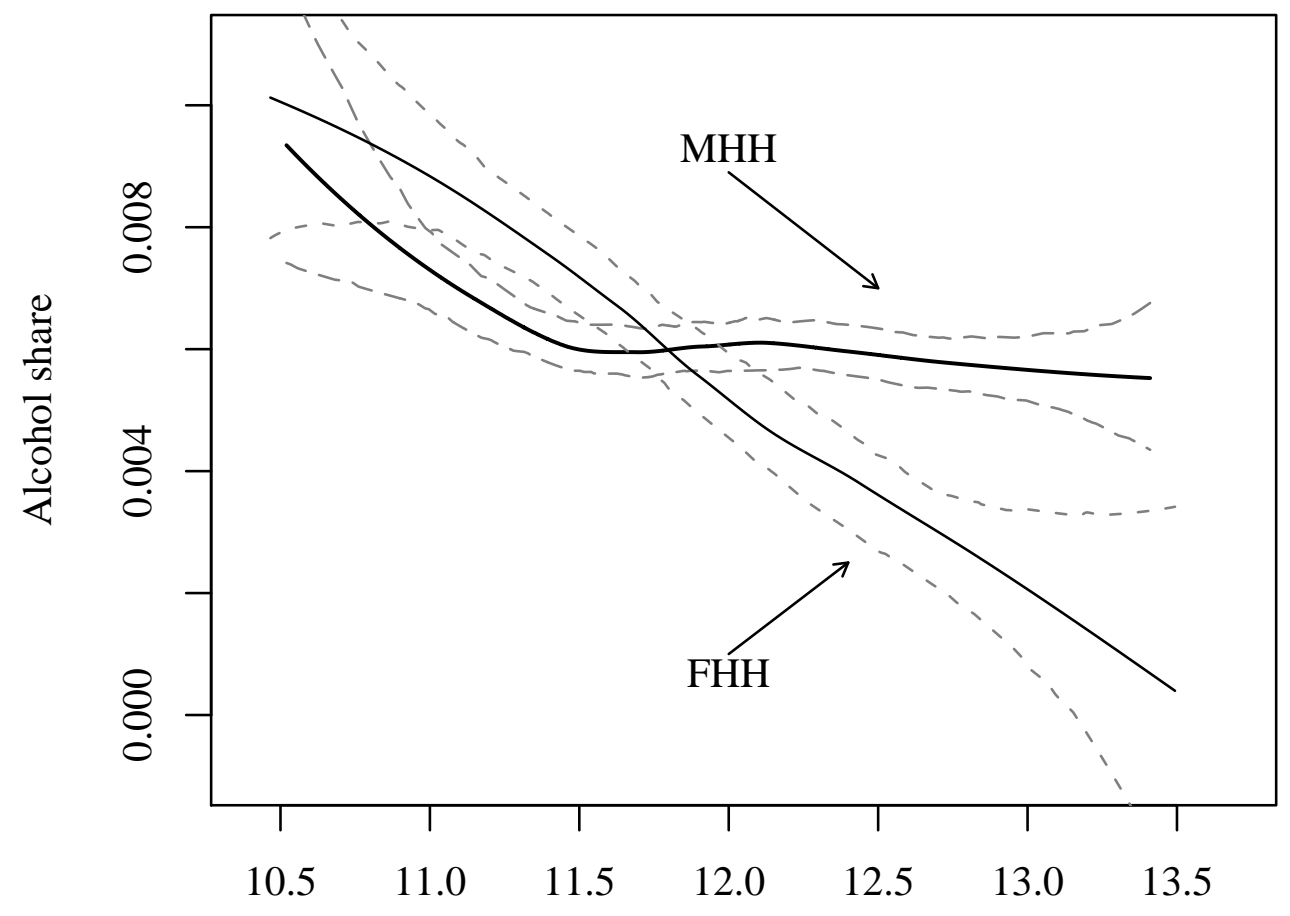

Log of total expenditure per capita

most closely translates one curve into the other and check whether these parameters are significantly different from zero. In case the parameters are significant, the difference (or remoteness) of the curves would have been established. The second hypothesis is concerned with the similarity of the shape of the two curves. If both household categories exhibit the same pattern of expenditure for the different goods, although at different levels of expenditure, then the curves should be parallel. The first step of the test involves the estimation of a single index model of the form

$$
w_{i}=m\left(\ln \left(x_{i}\right)-\delta c_{i}\right)+\alpha c_{i}+\varepsilon_{i}
$$

where $c$ denotes a dummy variable taking on the value 1 for $\mathrm{FHH}$ and 0 otherwise. The parameter $\delta$ causes a horizontal shift of the curve of FHH toward the MHH curve, while $\alpha$ leads to a vertical scaling. Equation (15) 
Figure 5: Budget shares for tobacco in FHH and MHH

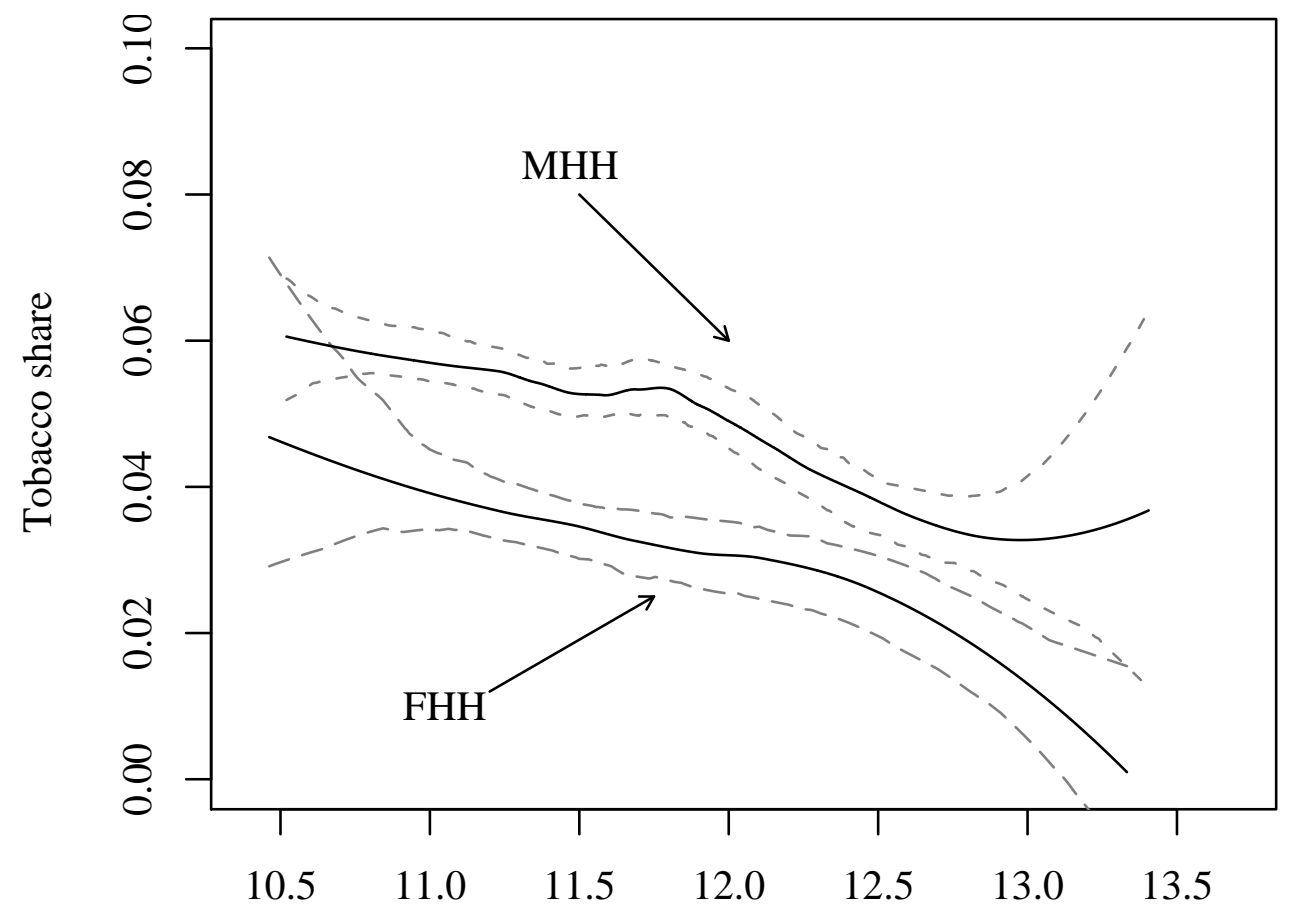

Log of total expenditure per capita

is estimated by applying the differencing method as proposed by Yatchew, Sun and Deri (2003), described in appendix 1. The results are presented in Table 3. The estimated scale parameters $\alpha$ shown in the first row are all significant at the 5-percent level thus statistically establishing the vertical distance between the demand curves and confirming the visual difference of the curves. Only the shift parameters $\beta$ presented in the third row of 3 are insignificant for non-food items, but significant for food.

The second part of the test evaluates whether the two regression curves exhibit the same shape. The test proceeds along the lines of the differencing procedure that has been used for calculating the parameters of the index model (see appendix 2). The estimated shift and scales are used to superimpose the curves by transforming the data of FHH. Then, the residual sum of squares of each curve separately is calculated as well as the sum of squares for the pooled data set. The test checks whether the weighted combination 
of the sum of squares of the individual curves is significantly different from the sum of squares of the pooled data. If the test statistic is significantly different from zero the curves are not parallel. The test statistic $\Upsilon$ follows a standard normal distribution and exhibits values that in all cases, but for education, are large enough to reject the parallelity of the curves at the 5 percent level. These results together with the significant distance between the curves establish that the demand for the different goods appears to follow a different pattern for FHH and MHH.

The results presented so far establish different patterns of expenditure on child and adult goods among FHH and MHH. The results, however, do not yet allow for inference on the welfare of children. Only the curves generated for child clothing allow this conclusion as this is an exclusive child good. Whether children really affect household demand requires the analysis of the model parameters.

\subsubsection{Household expenditure and children}

The parametric part of the models is given in tables 5 to 9 . To compare the parameters across models, I apply a Chow-like Wald test. Let $\hat{V}$ denote the variance-covariance matrix and $\hat{\beta}$ the estimated parameters generated by the regressions using FHH and MHH data respectively. A Wald test for the equality of the parameters across the two models of the form

$$
W=\left(\hat{\beta}_{f h h}-\hat{\beta}_{m h h}\right)^{\prime}\left(\hat{V}_{f h h}+\hat{V}_{m h h}\right)^{-1}\left(\hat{\beta}_{f h h}-\hat{\beta}_{m h h}\right) \sim \chi_{k}^{2}
$$

yields the results reported in table 4 . All sets of parameters, but those for alcohol, turn out to be significantly different at the 5 percent level for $\mathrm{MHH}$ and FHH. For food demand, the coefficients of the log of household size are negative for both types of households, implying that larger households have smaller per capita food expenditures. This finding corresponds to the results of Deaton and Paxson (1998), who demonstrate a negative relationship between household size and expenditure for food for several household surveys from developed and developing countries. This result is contrary to the expectation that because food is an entirely private good there are no economies of scale.

Small children do not affect food demand in neither household category. The same result applies to children in FHH of the age category 5 to 10 years. 
Older girls impose a negative effect in FHH as well as adult males and females do. Within MHH, boys from age 5 to 10 positively affect food demand while neither juveniles nor adults of any sex appear to influence $\mathrm{MHH}$ food demand. The results imply that FHH distribute food equally among small children and do not discriminate between sexes. Changes of food demand patterns are mainly governed by adults as well as by total household size. This is even more pronounced for MHH where food demand is almost entirely determined by household size and not by demographic composition, although the positive parameter for boys age 5 to 10 implies discrimination against girls at the same age. However, in this respect the important result is the coefficient for household size which is larger for MHH meaning that an additional household member regardless of which age and sex decrease the food share at a larger rate. This is different among FHH, where the negative parameters for juvenile girls and adults imply that food shares decrease particularly in response to these groups. All other effects of additional household members are governed by total household size where the estimate is smaller in absolute value suggesting, that small children fare on average better within FHH. This effect becomes even stronger when recalling that food shares among FHH are already higher. These positive results in terms of child welfare in FHH are slightly dampened by the observation that female education decreases food spending in $\mathrm{FHH}$ at a faster rate as compared to $\mathrm{MHH}$.

Total household size exerts no effect on child clothing demand within FHH but does so in MHH. The household composition parameters for children are significant in both models and are consistently larger within $\mathrm{MHH}$ compared to FHH. Interestingly, both models reveal a slight preference for girls from age zero to 10, which may be explained by possible higher prices for girl's clothing. Adults in FHH affect household demand for child clothing negatively while the respective estimates in $\mathrm{MHH}$ are positive though not significant at the 5 percent level. The parameters suggest that demand for child clothing is less responsive to an additional child in FHH. This may not tell the entire story, if women as head of household are more engaged in the maintenance of child clothing. Education exhibits a pattern different from clothing. Household size exerts a larger, positive influence on household expenditure for education in FHH. Estimates for juveniles are positive in both household categories, but larger in FHH. Given the fact that education ex- 
penditure is due for children of age $6+,{ }^{18}$ the fact that $\mathrm{FHH}$ parameters for small children are negative and larger in absolute value indicates a more efficient allocation of resources spent on education within FHH. As for clothing, both household categories exhibit a slight preference for girls of school age. Another interesting finding is that no differences between rural and urban households are apparent in FHH, while rural MHH spend significantly less on education. Furthermore, the effect from education on clothing expenditure is larger within FHH. In sum, in terms of clothing, FHH reveal do not reveal larger preferences for children, but do so with regard to education expenditure.

Demographic composition estimates reveal a surprising pattern for tobacco and alcohol. All parameters concerning the shares of children are significant and positive. This is a surprising result as it seems to suggest that children participate in the consumption of alcohol and tobacco. It is difficult to explain such pattern and only a few ad hoc explanations are available: (i) the excluded category 'elder people beyond age 60 significantly decrease consumption of tobacco and alcohol, (ii) cigarettes and alcohol consumption is related to greater fertility, (iii) cigarette and alcohol consumption works as a compensation for stress that is exerted from children. Regarding the first explanation, all demographic share parameters need to be interpreted with respect to the excluded category elderly people. ${ }^{19}$ Dropping small children and including the share of elderly in the equations turns the signs of almost all parameters into negative, while many lose their significance. The parameter for the share of elderly people above age 60 is negative and significant. Testing the reasoning behind the other two arguments, which are highly speculative, is beyond the scope of this paper and cannot be done given the data.

In interpreting the parameters for alcohol and tobacco it is revealing to consider again the fact that among FHH only 16 percent purchase any tobacco and 20 percent spend money on alcohol. The shares of MHH purchasing tobacco and alcohol are larger and amount to 30 and 31 percent respectively. Given such different expenditure propensities, the first stage probit models are useful for investigating the decision of purchasing these

\footnotetext{
${ }^{18}$ Public primary schooling is exempted from the requirement of paying fees.

${ }^{19}$ This is similar with dummy variables indicating a set of qualitative characteristics, where one dummy has to be excluded to avoid multicollinearity. All resulting dummy coefficients need to be evaluated against the excluded category.
} 
goods at all.

Table 10 shows the marginal effects of the first stage probit estimations for education and child clothing. The marginal effects for children of the clothing model are slightly larger among $\mathrm{MHH}$, although the difference between household categories is not substantial. However, this difference is compensated by the fact that FHH generally spend more on clothing compared with MHH. The same holds for education where the coefficients representing children imply that $\mathrm{MHH}$ are more responsive to children when investing in education. Again, FHH generally spend slightly more on education although the difference is not significant.

The demographic coefficients for alcohol and tobacco show a very clear pattern: children in FHH reduce expenditure on adult goods, while the respective coefficients for $\mathrm{MHH}$ are even positive for alcohol. Child share estimates are negative and significant for tobacco, but are in size always more than twice the value of $\mathrm{MHH}$ coefficients. A further interesting result is that among FHH, male adults appear to be the driving force behind the decision to consume tobacco which becomes apparent from the significantly positive coefficient, while the respective parameter in $\mathrm{MHH}$ is insignificant. Adult females on the other hand, negatively affect the purchasing decision in both categories, although the absolute effect is larger in $\mathrm{MHH}$.

\section{The old-age security hypothesis}

The old-age security hypothesis predicts that in the absence of savings, parents invest more in health and education of their children. One basic means to secure health is adequate nourishment, which can be achieved through a diet that provides not only calories but also necessary vitamins. The latter is often contained in food which is more expensive as for example vegetables and fruits. Education often implies an improvement of productivity and an increased likelihood to find a job on the wage labor market. Higher incomes lead to a larger set of options to financially support parents during old age. Therefore, educating children may be regarded as a means to secure old age security through remittances.

The variable used to indicate alternatives to children as old age security is savings. Unfortunately, the available data contains no information on the amount of the savings account, but only indicate if the household saves. The 
other means to secure old age welfare are assets. These assets are difficult to capture as not many are useful as an old age security investment due to their depreciation over time. The most effective asset is probably land, but given the underdeveloped markets for land and the precarious situation of land rights of women in Tanzania (Yngstrom 2002), it can hardly be regarded as an old age security for women. Including the size of available land in the regressions does not yield any significant results-neither for FHH nor MHH. Consequently, in what follows I rely on savings only.

In the first step, I introduce the savings dummy into the demand equations for food and education. Secondly, I add 6 interaction terms, where the share of each child age and sex group in total household size is interacted with the savings variable to investigate how the presence of children in the demand equations responds to savings. If $\mathrm{FHH}$ invest in children because of the lack of options to save money for old age, then the savings variable should yield a negative parameter. The savings parameter in the food demand equations reported in table 12 turns out to be significantly negative in both, FHH and MHH, regressions. The absolute value of the parameter is larger in FHH than in MHH; saving households spend on average between 6 and 4 percentage points less for food, respectively. To compare the impact from savings on food demand in the two household categories, I impose the savings effect on the demand curve which is graphed in figure 6 . The dashed line denotes the curves from $\mathrm{MHH}$, while the confidence intervals are left out to facilitate the exposition. The graph reveals that after imposing the impact from savings, the demand curves coincide fairly well compared to the benchmarks for 'non-savers' located above the curve denoting the 'savers. This result is conform to the hypothesis that parents invest in children to secure support in times of old age.

The interaction terms capture the impact of savings on the demographic parameters. None of the interaction terms is significant at the 5 percent level in FHH. Children therefore do not appear to have much influence on the negative impact of savings on food demand. In $\mathrm{MHH}$, almost all interactions are insignificant as well. The coefficient for the interaction between juvenile boys and savings is significantly negative in $\mathrm{MHH}$, implying that this group even increases the effect from savings on food demand. Judging from the results of the food regressions, one may conclude that children are an investment good in both household categories. The higher food demand 
among FHH disappears as soon as a control for savings is introduced.

Regarding education, savings increase the budget share of education for both household categories. This may suggest that household heads save for the education of their children at older ages. However, the interaction terms are all, but for girls of age 11 to 15 , negative and significant for $\mathrm{MHH}$ implying that the positive impact of savings on education spending decreases with more children. Within FHH, only boys of age 5 to 10 and juvenile girls significantly reduce the positive impact of savings to educational spending. Even though, savings increase expenditure on education, the positive effect diminishes with increasing shares of children living in the household. The graph with savings imposed on the demand curves (figure 7) reveals that differences between $\mathrm{MHH}$ and FHH even become more pronounced among savers and non-savers.

In sum, the results from the education regressions do neither support nor reject the old age hypothesis since the positive effect running from savings on education implies a rejection while the negative interaction terms qualify the positive effect and rather speak for support the old age security assumption. It is unfortunately not obvious from the results whether households save for the education of their children or for the participation in adult training programs. Furthermore, it is not possible to conclude that households save for education at all and whether the savings variable captures another effect running from saving on education. Nevertheless, the results reveal some interesting patterns. It appears that among savers, spending on food and education is rather a substitute than a complement.

The test is subject to a number of problems: (i) the overall spread of saving accounts is rather low and therefore, savings may not represent all options that households have to accumulate assets. This might be particularly true for rural areas, where formal savings institutions are rarely available. However, the rural-urban dummy variable accounts to some extent for this fact. The major asset for rural households is land, which is almost a non-tradable good, since land is largely allocated through family relations (Yngstrom 2002) which might explain the insignificant coefficients for land. (ii) The results are difficult to interpret as savings are meant for future consumption while the measured expenditure shares refer to current consumption. (iii) Health and education may not be regarded by parents as a means to achieve improved old age support. (iv) The relationship be- 
Figure 6: Food demand curves for savers and non-savers

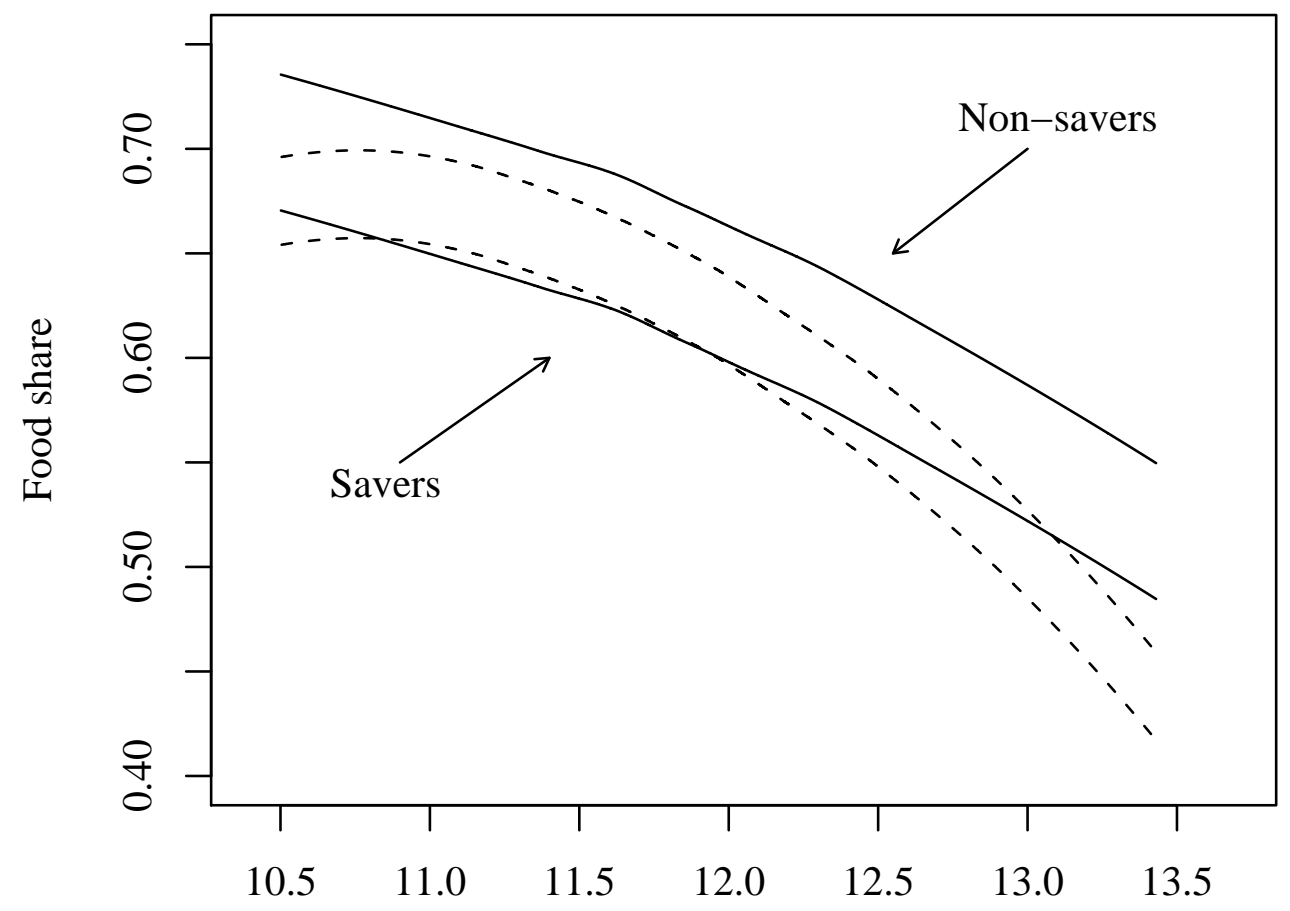

Log of total expenditure per capita

tween savings and spending might be dependent on the level of income. In the present formulation, the savings parameter is assumed to be stable across the whole range of expenditure. However, it is likely that poorer households do not have sufficient monetary surplus that would allow them to save enough to keep their living standard during old age. But these are the households where it is expected that households need child support and ergo healthy and well educated children most. (v) Increased expenditure for food may not be associated with improved nourishment and health. The data does unfortunately not allow for deriving the nutritional status of children within saving households in order to trace different compositions of the food baskets among savers and non-savers. However, it has been found for Malawi that children from FHH exhibits higher levels of nourishment (Kennedy and Peters 1992). Although the authors do not report spending behavior of the households, the finding is conform to the higher food share 
Figure 7: Education demand curves for savers and non-savers

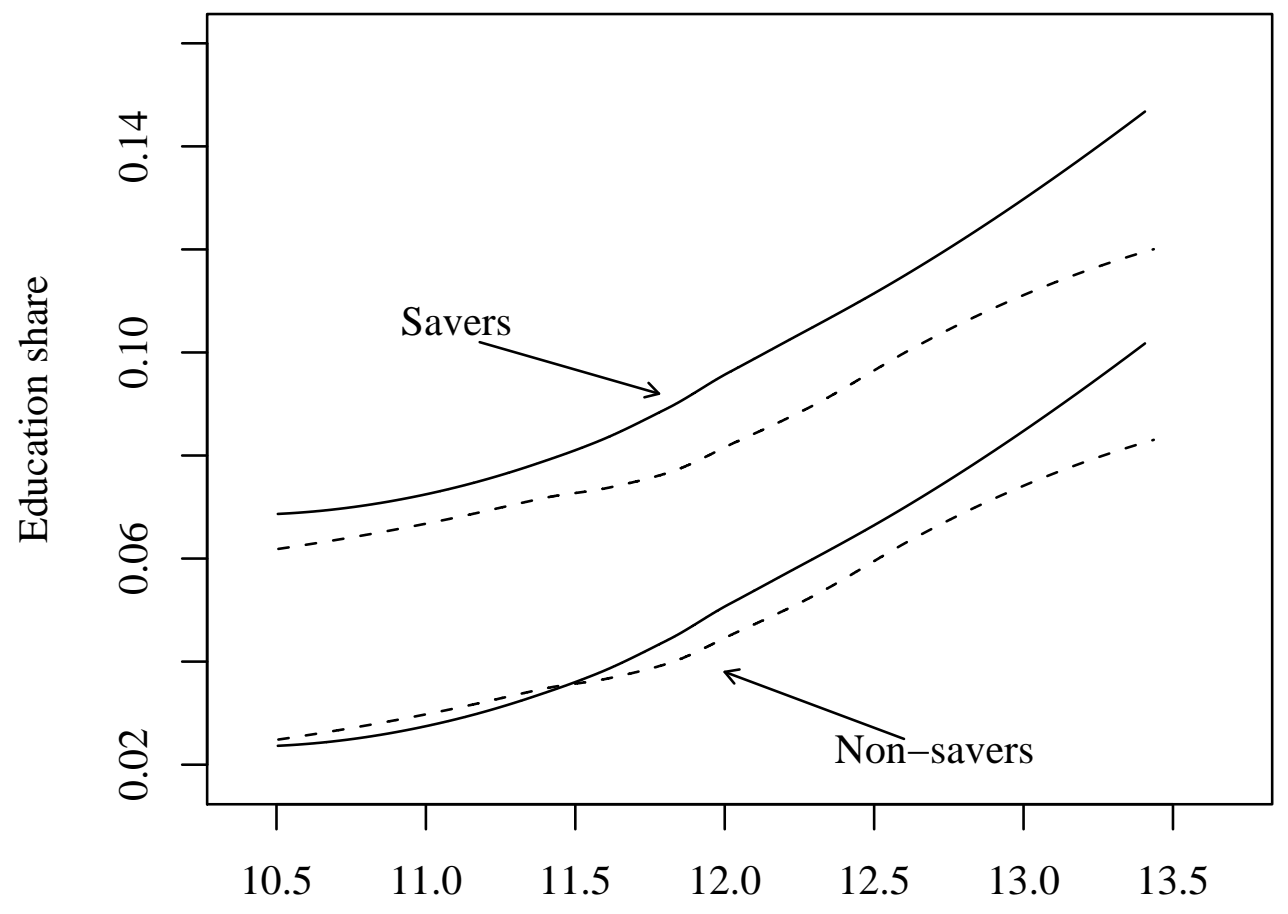

Log of total expenditure per capita

found in Tanzania.

\section{Conclusions}

In this study I have investigated patterns of demand and their implications for child welfare across FHH and MHH. The results reveal significantly different expenditure patterns where FHH spend more toward the welfare of their children and less on personal consumption of the adult goods alcohol and tobacco. The findings on the old age hypothesis demonstrate despite their weaknesses a significant relationship between savings and spending. Savings significantly reduce spending for food in both household categories. The demand patterns become even very similar after imposing the influence of savings on the demand curves. This finding is consistent with the old age security hypothesis, according to which FHH spend more on food because 
women treat children as an investment good. This explanation is in contrast to the common view that women spend more on children because they are and get closer to them during pregnancy, birth and subsequent child hood. However, the results from the education regressions do not unambiguously support the old age hypothesis since education spending increases with savings. Although the presence of children overcompensates the positive effect it is not easy to think of explanations for this finding. One possibility is, that parents save and spend rather on their own education and adult training programs as on the education of their children. Unfortunately, the data does not differentiate between spending on child or adult education. If this is true, then this finding would further support the old age hypothesis. However, further research is needed in order to differentiate between spending on adult and child training and that allows for including the amount of savings available in order to track dependencies of the link between savings and spending behavior across different levels of income. The results should therefore be treated as a first step in the testing of the old age security hypothesis.

The findings are also relevant for the literature on intrahousehold bargaining over resources. On the one hand, the results support the common finding that women spend more on the welfare of their children. Policies that transfer money to mothers and not to fathers are more likely to translate into increases of child welfare as if the money would be given to fathers. This assumption has been fruitfully applied in the Mexican PROGRESA project, where child education has significantly improved. If the motive behind the higher spending of women is grounded in the old security motive, then policies that grant monetary transfers to mothers exclusively may fail under circumstances where women have other means to insure against old age poverty. More research on this subject would be useful, particularly in the context of developing and developed countries, where in the latter, the conditions for old age security which is independent from children are more likely to hold. Studies on spending behavior and welfare of children are mostly restricted to the developing world. To arrive at a conclusion on this matter, however, such comparisons are needed. 


\section{References}

Amemiya, T.: 1985, Advanced Econometrics, Basil Blackwell, Oxford.

Barbieri, M. and Hertrich, V.: 2005, Age difference between spouses and contraceptive practice in sub-Saharan Africa, Population 60(5-6), 617654.

Behrman, J. and Deolalikar, A.: 1987, Will developing country nutrition improve with rising income? A case study for rural South India, Journal of Political Economy 95(3), 492-507.

Bhalotra, S. and Attfield, C.: 1998, Intrahousehold resource allocation in rural Pakistan: A semiparametric analysis, Journal of Applied Econometrics 13(5), 463-480.

Blundell, R., Duncan, A. and Pendakur, K.: 1998, Semiparametric estimation and consumer demand, Journal of Applied Econometrics 13(5), 435-461.

Browning, M. and Chiappori, P.-A.: 1998, Efficient intra-household resource allocations: a general characterization and empirical tests, Econometrica 66(6), 1241-1278.

Bruce, J.: 1989, Homes divided, World Development 17(7), 979-992.

Cain, M.: 1981, Risk and insurance: Perspecties on fertility and agrarian change in India and Bangladesh, Population and Development Review $7(3), 435-474$.

Cain, M.: 1982, Perspectives on family and fertility in developing countries, Population and Development Review 36(2), 159-175.

Cain, M.: 1983, Fertility as an adjustment to risk, Population and Development Review 9(4), 688-702.

Chiappori, P.-A.: 1992, Collective labor supply and welfare, Journal of Political Economy 100(3), 437-467.

Cigno, A.: 1993, Intergenerational transfers without altruism. Family, market and state, European Journal of Political Economy 9, 505-518. 
Cleveland, W.: 1979, Robust locally weighted regression and smoothing scatterplots, Journal of the American Statistical Association 74, 829836.

Cragg, J.: 1971, Some statistical models for limited dependent variables with application to the demand of durable goods, Econometrica 39, 829-844.

Davidson, R. and MacKinnon, J. G.: 2004, Econometric theory and methods, Oxford University Press, Oxford.

Deaton, A. and Paxson, C.: 1998, Economies of scale, household size, and the demand for food, Journal of Political Economy 106(5), 897-930.

Deaton, A., Ruiz-Castillo, J. and Thomas, D.: 1989, The influence of household composition on household expenditure patterns: Theory and Spanish evidence, Journal of Political Economy 97(1), 179-200.

Gorman, W. M.: 1981, Some engel curves, in A. Deaton (ed.), Essays in Honour of Sir Richard Stone, Johns Hopkins University Press, Cambridge, pp. 1-10.

Gozalo, P.: 1997, Nonparametric bootstrap analysis with applications to demographic effects in demand functions, Journal of Econometrics 81, 357-393.

Haddad, L.: 1999, The earned income by women: impacts on welfare outcomes, Agricultural Economics 20, 135-141.

Haddad, L. and Hoddinott, J.: 1994, Women's income and boy-girl anthropometric Status in the Côte D'Ivoire, World Development 22(4), 543553.

Handa, S.: 1994, Gender, headship, and intra-household resource allocation, World Development 22(10), 1535-1547.

Handa, S.: 1996, Expenditure behavior and children's welfare: An analysis of female headed households in Jamaica, Journal of Development Economics 50, 165-187.

Härdle, W. and Marron, J.: 1990, Semiparametric comparison of regression curves, Annals of Statistics 18(1), 63-89. 
Härdle, W., Müller, M., Sperlich, S. and Werwatz, A.: 2004, Nonparametric and semiparametric models, Springer, Berlin.

Hausman, J.: 1978, Specification tests in econometrics, Econometrica 646, 1251-1271.

Heckman, J.: 1976, The common structure of statistical models of truncation, sample selection and limited dependent variables and a simple estimator for such models, Annals of Economic and Social Measurement 5, 475-492.

Heckman, J.: 1979, Sample selection bias as a specification error, Econometrica 1, 153-161.

Kennedy, E. and Peters, P.: 1992, Household food security and child nutrition: the interaction of income and gender of the household head, World Development 20(8), 1077-1085.

Maddala, G.: 1983, Limited-dependent and qualitative variables in econometrics, Cambridge University Press, Cambridge.

Manser, M. and Brown, M.: 1980, Marriage and household decision-making: A bargaining analysis, International Economic Review 21(1), 31-44.

McElroy, M. B. and Horney, M. J.: 1981, Nash-bargained household decisions: Toward a generalization of the theory of demand, International Economic Review 22(2), 333-349.

Nugent, J.: 1985, The old age security motive for having children, Population and Development Review 11(1), 75-98.

Nugent, J. B. and Gillaspy, T. R.: 1983, Old age pensions and fertility in rural areas of less developed countries: Some evidence from Mexico, Economic Development and Cultural Change 31(4), 809-829.

Pendakur, K.: 1999, Estimates and tests of base-independent equivalence scales, Journal of Econometrics 88(1), 1-40.

Quisumbing, A. and Maluccio, J.: 2000, Intrahousehold allocation and gender relations: new empirical evidence from four developing countries, FCND Discussion Paper No. 84, International Food Policy Research Institute (IFPRI), Washington D.C. 
Rilstone, P. and Ullah, A.: 1989, Nonparametric estimation of response coefficients, Communications in Statistics, Theory and Methods 18, 669680.

Robinson, P.: 1988, Root-n-consistent semiparametric regression, Econometrica 56, 931-954.

Rogers, B. L.: 1996, The implications of female household headship for food consumption and nutritional status in the Dominican Republic, World Development 24(1), 113-128.

Ruppert, D., Wand, M. and Carroll, R. J.: 2003, Semiparametric Regression, Cambridge University Press, Cambridge.

Shonkwiler, J. and Yen, S.: 1999, Two-step estimation of a censored system of equations, American Journal of Agricultural Economics 81(4), 972982.

Speckman, P.: 1988, Kernel smoothing in partial linear models, Journal of the Royal Statistical Society, B 50, 413-436.

Tauchmann, H.: 2005, Efficiency of two-step estimators for censored systems of equations: Shonkwiler and Yen reconsidered, Applied Economics 37, 367-374.

Thomas, D.: 1990, Intra-household resource allocation: An inferential approach, Journal of Human Resources 25(4), 635-664.

Thomas, D.: 1993, The distribution of income and expenditure within the household, Annales de Economie et de Statistique 29, 109-136.

Thomas, D.: 1994, Like father, like son; like mother, like daughter: Parental resources and child height, Journal of Human Resources 29, 950-988.

Thomas, D., Lavy, V. and Strauss, J.: 1996, Public policy and anthropometric outcomes in the Côte d'Ivoire, Journal of Public Economics 61(2), 155-192.

Thomas, D. and Strauss, J.: 1992, Prices, infrastructure, household characteristics and child height, Journal of Political Economy 39(2), 301-331. 
Ullah, A.: 1988, Nonparametric estimation and hypothesis testing in econometric models, Empirical Economics 13, 223-249.

United Republic of Tanzania: 2002, Integrated Labour Force Survey 2000/01. Analytical Report.

Wooldridge, J.: 2002, Econometric analysis of cross section and panel data, MIT Press, Cambridge.

Yatchew, A.: 1999, An elementary nonparametric differencing test of equality of regression functions, Economics Letters 62, 271-278.

Yatchew, A., Sun, Y. and Deri, C.: 2003, Efficient estimation of semiparametric equivalence scales with evidence from South Africa, Journal of Business 83 Economic Statistics 21(2), 247-57.

Yngstrom, I.: 2002, Women, wives and land rights in Africa: Situating gender beyond the household in the debate over land policy and changing tenure systems, Oxford Development Studies 30(1), 21-40. 
Table 1: Summary statistics

\begin{tabular}{|c|c|c|c|c|}
\hline & \multicolumn{2}{|r|}{$\mathrm{FHH}$} & \multicolumn{2}{|c|}{$\mathrm{MHH}$} \\
\hline & Mean & Standard dev. & Mean & Standard dev. \\
\hline Food share & 0.666 & 0.145 & 0.637 & 0.152 \\
\hline Alcohol share & 0.014 & 0.056 & 0.024 & 0.066 \\
\hline Tobacco share & 0.032 & 0.045 & 0.049 & 0.063 \\
\hline Education share & 0.047 & 0.071 & 0.044 & 0.068 \\
\hline Clothing share & 0.028 & 0.031 & 0.025 & 0.031 \\
\hline Log Expenditure per capita & 11.864 & 0.652 & 11.884 & 0.631 \\
\hline Log Hhldsize & 1.159 & 0.660 & 1.415 & 0.656 \\
\hline Boys 0-4 & 0.064 & 0.132 & 0.072 & 0.119 \\
\hline Girls 0-4 & 0.064 & 0.132 & 0.072 & 0.118 \\
\hline Boys $5-10$ & 0.062 & 0.123 & 0.063 & 0.107 \\
\hline Girls 5-10 & 0.068 & 0.129 & 0.060 & 0.105 \\
\hline Boys 11-15 & 0.052 & 0.112 & 0.043 & 0.089 \\
\hline Girls 11-15 & 0.058 & 0.120 & 0.043 & 0.088 \\
\hline Male adults & 0.102 & 0.161 & 0.337 & 0.258 \\
\hline Female adults & 0.423 & 0.290 & 0.247 & 0.155 \\
\hline Primary education & 0.387 & 0.487 & 0.526 & 0.499 \\
\hline Secondary education & 0.093 & 0.291 & 0.161 & 0.368 \\
\hline Age & 44.028 & 15.291 & 42.524 & 14.295 \\
\hline Rural & 0.312 & 0.463 & 0.363 & 0.481 \\
\hline Log available land & 0.755 & 0.783 & 0.964 & 0.939 \\
\hline Savings & 0.091 & 0.288 & 0.142 & 0.349 \\
\hline
\end{tabular}

Table 2: Shares of households purchasing goods

\begin{tabular}{lllll}
\hline \hline & \multicolumn{2}{c}{ Purchase FHH } & \multicolumn{2}{c}{ Purchase MHH } \\
& Yes & No & Yes & No \\
\hline Alcohol & 0.20 & 0.80 & 0.30 & 0.70 \\
Tobacco & 0.16 & 0.84 & 0.31 & 0.69 \\
Clothing & 0.60 & 0.40 & 0.65 & 0.35 \\
Education & 0.51 & 0.49 & 0.52 & 0.48 \\
\hline \hline
\end{tabular}

Table 3: Estimated scale and shift parameters*

\begin{tabular}{lccccc}
\hline \hline & Food & Clothing & Education & Alcohol & Tobacco \\
\hline Scale Parameter $\alpha$ & 0.037 & 0.002 & 0.006 & -0.001 & -0.016 \\
& $(0.002)$ & $(0.001)$ & $(0.001)$ & $(0.000)$ & $(0.002)$ \\
Shift Parameter $\delta$ & 0.170 & -0.110 & 0.110 & 0.040 & -0.160 \\
& $(0.037)$ & $(0.143)$ & $(0.082)$ & $(0.251)$ & $(0.431)$ \\
$\Upsilon$ & 13.043 & 1.450 & 1.310 & 8.075 & 11.997 \\
$\mathrm{p}$ & 0.000 & 0.147 & 0.190 & 0.000 & 0.000 \\
\hline \hline * Associated p-values in parentheses.
\end{tabular}

*Associated p-values in parentheses. 
Table 4: Wald test for difference of parameters

\begin{tabular}{crrrrr}
\hline \hline & Food & Clothing & Clothing & Alcohol & Tobacco \\
\hline$\chi_{32}^{2}$ & 75.809 & 50.441 & 48.603 & 73.694 & 33.900 \\
p-value & 0.000 & 0.020 & 0.030 & 0.000 & 0.376 \\
\hline \hline
\end{tabular}


Table 5: Parameters of the semiparametric model - Food

\begin{tabular}{lccrr}
\hline \hline & FHH & \multicolumn{2}{c}{ MHH } \\
& Parameter & t-value & Parameter & t-value \\
\hline ln Hhldsize & $-0.048 * *$ & -12.656 & $-0.063 * *$ & -24.197 \\
Boys 0-4 & -0.001 & -0.104 & 0.013 & 1.320 \\
Girls 0-4 & 0.006 & 0.405 & -0.000 & -0.037 \\
Boys 5-10 & 0.001 & 0.046 & $0.045 * *$ & 4.006 \\
Girls 5-10 & -0.006 & -0.436 & 0.018 & 1.593 \\
Boys 11-15 & -0.027 & -1.642 & -0.005 & -0.393 \\
Girls 11-15 & $-0.031 * *$ & -2.039 & -0.020 & -1.511 \\
Male adults & $-0.027 * *$ & -2.189 & -0.005 & -0.841 \\
Female adults & $-0.039 * *$ & -4.516 & $-0.012 * *$ & -1.484 \\
Primary education & $-0.029 * *$ & -5.807 & $-0.019 * *$ & -6.456 \\
Secondary education & $-0.086 * *$ & -11.292 & $-0.051 * *$ & -13.411 \\
Age & -0.000 & -0.094 & $0.000 * *$ & 4.713 \\
Rural & $0.029 * *$ & 6.722 & $0.029 * *$ & 11.754 \\
F & & & & $p: 0.000$ \\
N & 20.346 & $p: 0.000$ & 59.491 & 14,046 \\
\hline ** significant at 5 percent level & 4,737 & & & \\
\hline
\end{tabular}

** significant at 5 percent level 
Table 6: Parameters of the semiparametric model - Clothing

\begin{tabular}{|c|c|c|c|c|}
\hline & \multicolumn{2}{|l|}{$\mathrm{FHH}$} & \multicolumn{2}{|l|}{$\mathrm{MHH}$} \\
\hline & Parameter & t-value & Parameter & t-value \\
\hline ln Hhldsize & 0.002 & 1.028 & $0.002 * *$ & 2.340 \\
\hline Boys 0-4 & $0.032 * *$ & 8.522 & $0.043 * *$ & 13.781 \\
\hline Girls 0-4 & $0.036 * *$ & 9.510 & $0.046 * *$ & 14.718 \\
\hline Boys $5-10$ & $0.029 * *$ & 7.272 & $0.039 * *$ & 12.468 \\
\hline Girls 5-10 & $0.032 * *$ & 8.291 & $0.046 * *$ & 14.522 \\
\hline Boys 11-15 & $0.019 * *$ & 4.585 & $0.038 * *$ & 11.267 \\
\hline Girls 11-15 & $0.031 * *$ & 7.283 & $0.037 * *$ & 10.459 \\
\hline Male adults & $-0.019 * *$ & -3.538 & 0.001 & 0.197 \\
\hline Female adults & -0.006 & -1.424 & 0.004 & 1.092 \\
\hline Primary education & $0.004 * *$ & 2.657 & $0.003 * *$ & 3.257 \\
\hline Secondary education & $0.007 * *$ & 3.295 & $0.004 * *$ & 3.805 \\
\hline Age & 0.000 & 0.017 & $0.000 * *$ & -3.179 \\
\hline Rural & $-0.004 * *$ & -3.372 & $-0.005 * *$ & -7.531 \\
\hline Mills & $0.015 * *$ & 5.013 & $0.012 * *$ & 5.955 \\
\hline $\mathrm{F}$ & 5.218 & $p: 0.000$ & 14.230 & $p: 0.000$ \\
\hline $\mathrm{N}$ & 3,067 & & 9,903 & \\
\hline
\end{tabular}

Table 7: Parameters of the semiparametric model - Education

\begin{tabular}{lcrrr}
\hline \hline & FHH & \multicolumn{2}{c}{ MHH } \\
& Parameter & t-value & Parameter & t-value \\
\hline ln Hhldsize & $0.058 * *$ & 8.748 & $0.050 * *$ & 14.483 \\
Boys 0-4 & -0.027 & -1.815 & $-0.026 * *$ & -2.764 \\
Girls 0-4 & $-0.034 * *$ & -2.191 & $-0.024 * *$ & -2.529 \\
Boys 5-10 & $0.061 * *$ & 5.939 & $0.058 * *$ & 7.878 \\
Girls 5-10 & $0.104 * *$ & 10.075 & $0.071 * *$ & 9.380 \\
Boys 11-15 & $0.152 * *$ & 11.563 & $0.131 * *$ & 15.349 \\
Girls 11-15 & $0.144 * *$ & 11.527 & $0.139 * *$ & 15.987 \\
Male adults & $0.057 * *$ & 5.329 & $0.080 * *$ & 13.888 \\
Female adults & $0.066 * *$ & 7.561 & $0.053 * *$ & 7.116 \\
Primary education & $0.015 * *$ & 4.164 & $0.017 * *$ & 8.734 \\
Secondary education & $0.041 * *$ & 7.826 & $0.041 * *$ & 17.536 \\
Age & $0.001 * *$ & 4.846 & $0.001 * *$ & 12.315 \\
Rural & -0.005 & -1.746 & $-0.009 * *$ & -5.388 \\
Mills & $0.065 * *$ & 6.724 & $0.049 * *$ & 10.500 \\
F & & & 37.803 & $p: 0.000$ \\
N & 10.119 & $p: 0.000$ & 7,934 & \\
\hline ** significant at 5 percent level & & & \\
\hline
\end{tabular}


Table 8: Parameters of the semiparametric model - Tobacco

\begin{tabular}{lcrrr}
\hline \hline & FHH & \multicolumn{2}{c}{ MHH } \\
& Parameter & t-value & Parameter & t-value \\
\hline ln Hhldsize & $-0.018 * *$ & -5.616 & $-0.034 * *$ & -16.786 \\
Boys 0-4 & $0.036 * *$ & 2.604 & $0.063 * *$ & 8.598 \\
Girls 0-4 & $0.041 * *$ & 3.162 & $0.054 * *$ & 7.020 \\
Boys 5-10 & $0.038 * *$ & 3.006 & $0.069 * *$ & 6.903 \\
Girls 5-10 & $0.044 * *$ & 3.305 & $0.056 * *$ & 5.866 \\
Boys 11-15 & $0.051 * *$ & 3.837 & $0.045 * *$ & 4.947 \\
Girls 11-15 & $0.030 * *$ & 2.141 & $0.074 * *$ & 6.433 \\
Male adults & $0.028 * *$ & 2.148 & $0.026 * *$ & 5.168 \\
Female adults & $0.025 * *$ & 3.454 & $0.038 * *$ & 4.660 \\
Primary education & 0.004 & 0.745 & $0.017 * *$ & 3.965 \\
Secondary education & 0.001 & 0.068 & $0.030 * *$ & 3.017 \\
Age & 0.000 & -0.039 & 0.000 & -1.181 \\
Rural & $-0.015 * *$ & -3.560 & $-0.029 * *$ & -5.740 \\
Mills & $-0.037 * *$ & -2.893 & $-0.089 * *$ & -3.774 \\
& & & & $p: 0.000$ \\
F & 1.779 & $p: 0.005$ & 16.769 & 4,798 \\
$\mathrm{~N}$ & 848 & & & \\
\hline \hline ** significant at 5 percent level & & & & \\
\hline
\end{tabular}

Table 9: Parameters of the semiparametric model - Alcohol

\begin{tabular}{|c|c|c|c|c|}
\hline & \multicolumn{2}{|l|}{$\mathrm{FHH}$} & \multicolumn{2}{|c|}{$\mathrm{MHH}$} \\
\hline & Parameter & t-value & Parameter & t-value \\
\hline ln Hhldsize & $-0.006 * *$ & -4.984 & $-0.004 * *$ & -8.816 \\
\hline Boys 0-4 & 0.003 & 1.307 & $0.004 * *$ & 4.148 \\
\hline Girls 0-4 & 0.003 & 1.049 & $0.003 * *$ & 2.961 \\
\hline Boys $5-10$ & $0.006 * *$ & 2.622 & $0.006 * *$ & 5.263 \\
\hline Girls 5-10 & $0.009 * *$ & 2.846 & $0.004 * *$ & 3.071 \\
\hline Boys 11-15 & $0.009 * *$ & 2.756 & $0.005 * *$ & 3.487 \\
\hline Girls 11-15 & $0.005 * *$ & 2.072 & $0.006 * *$ & 4.137 \\
\hline Male adults & $0.004 * *$ & 2.396 & $0.006 * *$ & 7.215 \\
\hline Female adults & $0.006 * *$ & 4.206 & $0.002 * *$ & 2.259 \\
\hline Primary education & 0.001 & -0.321 & 0.000 & -1.043 \\
\hline Secondary education & 0.000 & -0.676 & 0.001 & 1.759 \\
\hline Age & 0.000 & -0.603 & $0.000 * *$ & 4.702 \\
\hline Rural & -0.003 & -1.418 & $0.003 * *$ & 2.919 \\
\hline Mills & $-0.012 * *$ & -2.188 & $0.008 * *$ & 2.698 \\
\hline $\mathrm{F}$ & 2.869 & $p: 0.000$ & 16.503 & $p: 0.000$ \\
\hline $\mathrm{N}$ & 995 & & 4466 & \\
\hline
\end{tabular}




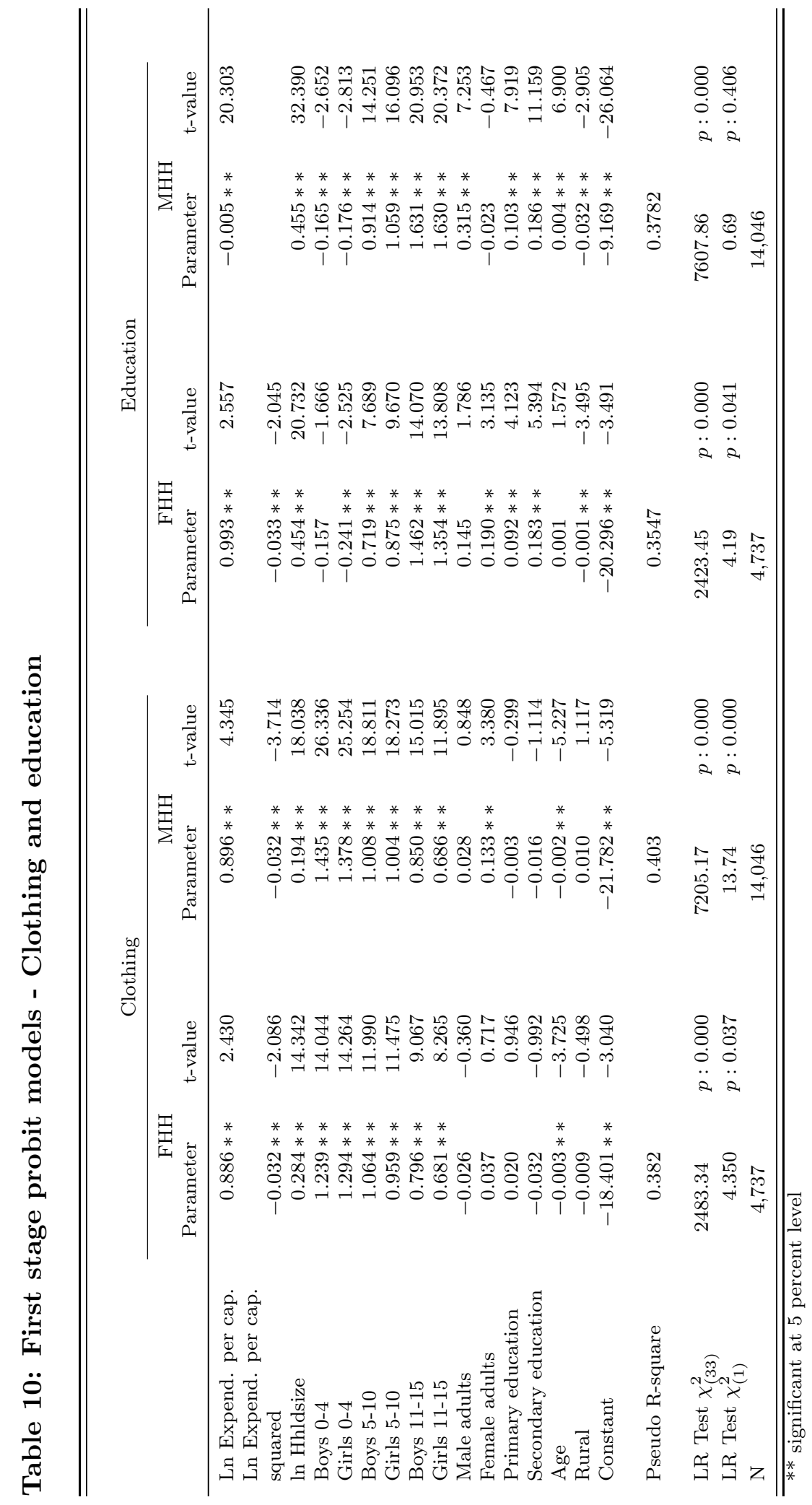




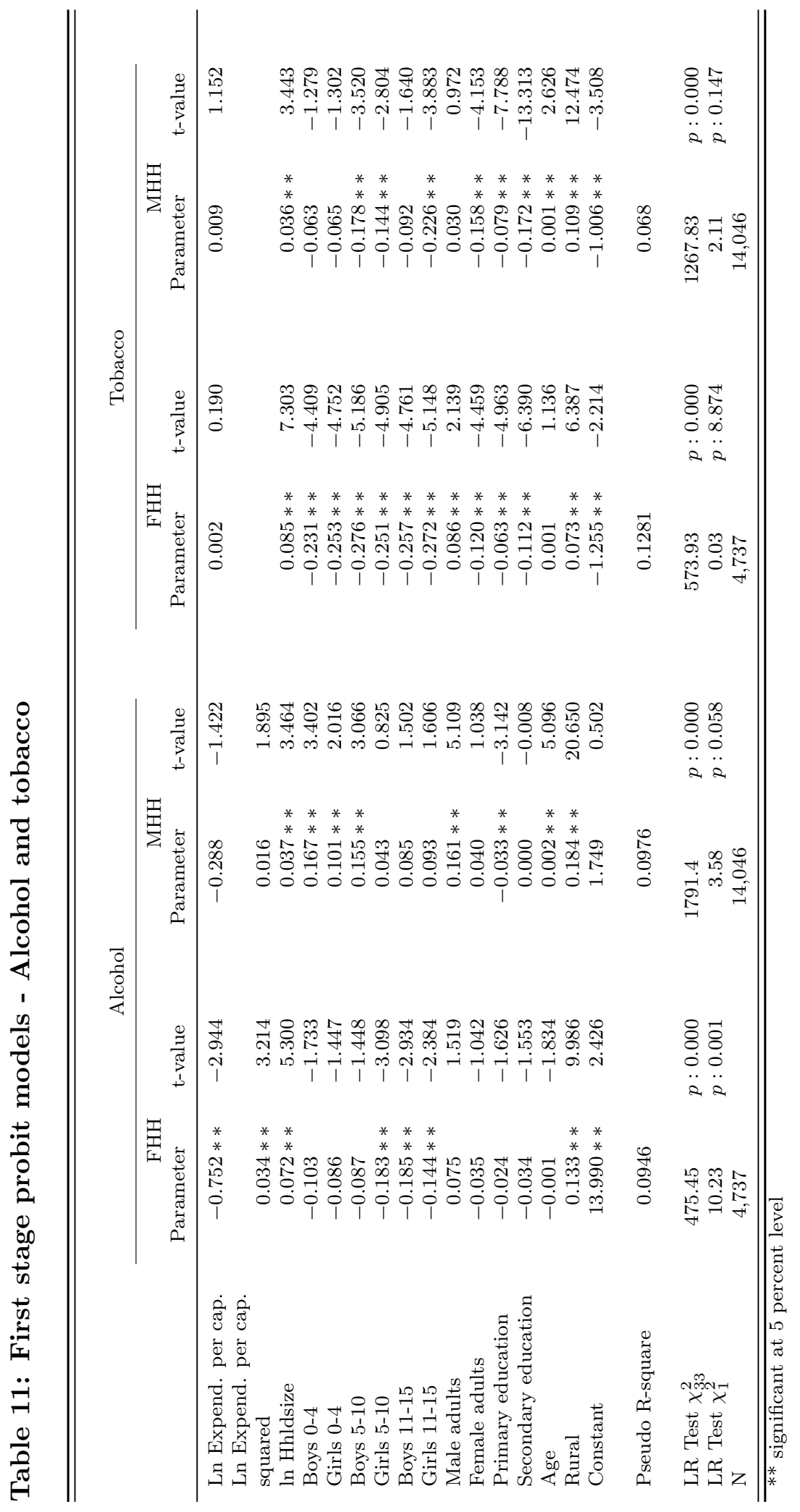




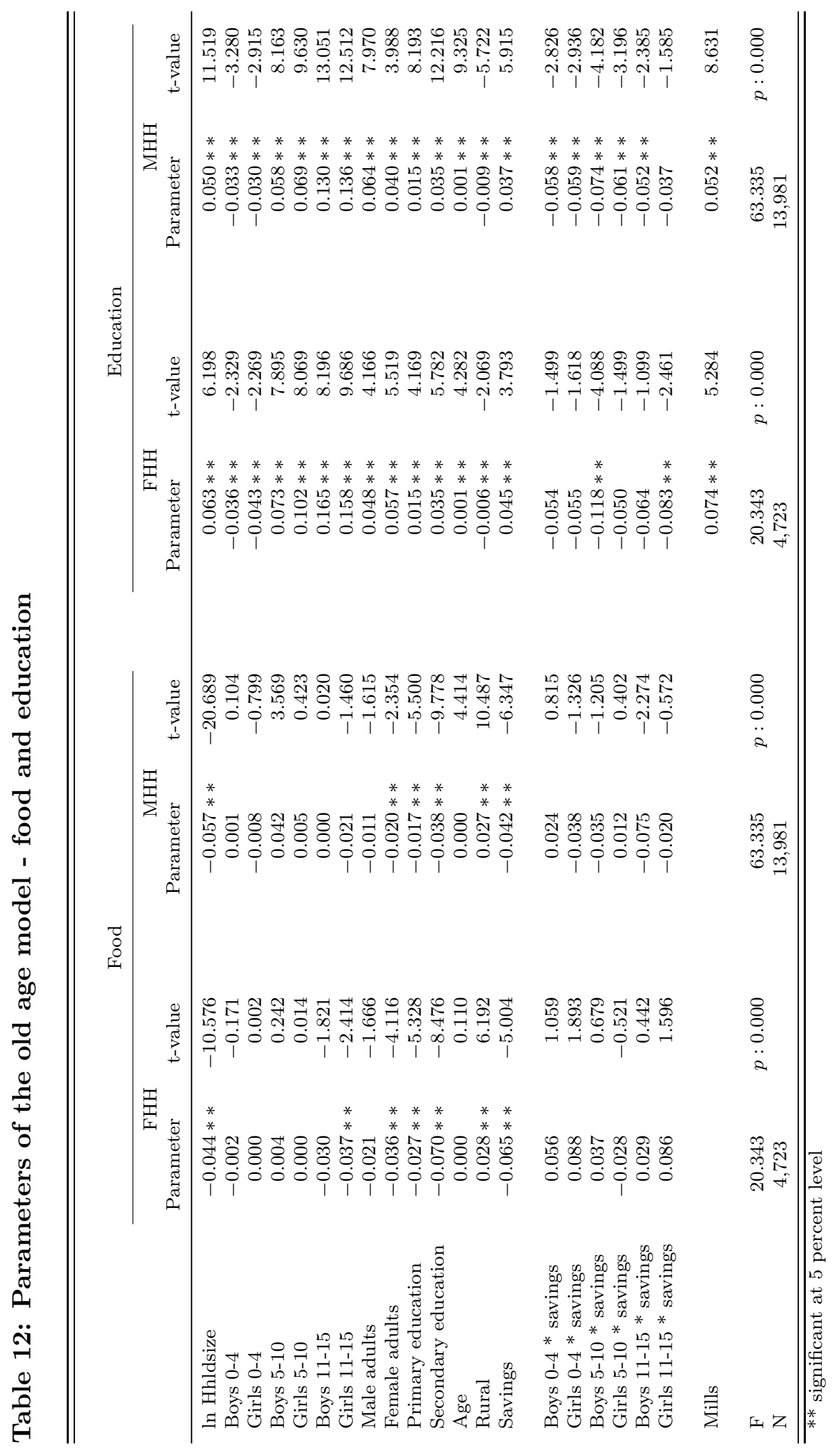




\section{Appendix}

\section{A.1. Estimating the transformation parameters $\alpha$ and $\beta$}

The model is estimated by applying the differencing procedure as proposed by Yatchew, Sun and Deri $(2003)^{20}$

$$
w_{i}=m\left(\ln x_{i}-\delta z_{i}\right)+\alpha z_{i}+\varepsilon_{i}
$$

The idea is to remove the nonparametric function by differencing it out which has the advantage that in the process of finding the parameter $\alpha$ and $\delta$ one does not need to compute the nonparametric function $m(\cdot)$. To achieve this, evaluate the nonparametric function $m\left(\ln x_{i}-\delta c_{i}\right)$ at some reasonably chosen parameter values $\delta$ and obtain observations $m$. The obervations $\left(y_{1}, m_{1}, z_{1}\right), \ldots,\left(y_{n}, m_{n}, z_{n}\right)$ have to be arranged with respect to $m_{i}$ in increasing order such that $m_{1} \leq m_{2} \leq \cdots \leq m_{n}$. Next, consider the differencing coefficients $d$ for which the conditions

$$
\sum_{i=1}^{J} d_{i}=0 \quad \text { and } \quad \sum_{i=1}^{J} d_{i}^{2}=1
$$

must hold. $J$ denotes here the order of differencing. The differencing coefficients have to arranged in a band matrix

$$
D=\left(\begin{array}{ccccccc}
d_{0}, & d_{1}, & \ldots, & d_{j}, & 0, & \ldots & 0 \\
0 & d_{0}, & d_{1}, & \ldots, & d_{j}, & \ldots & 0 \\
& \vdots & \vdots & \vdots & \vdots & & \\
0, & \ldots & d_{0}, & d_{1}, & \ldots & d_{j}, & 0 \\
0, & \ldots & 0 & d_{0}, & d_{1}, & \ldots & d_{j}
\end{array}\right)
$$

where $D$ is a $(n-j) \times n$ matrix. Next premultiply equation 17 with $D$ and obtain

$$
D y \cong D m(\ln x-\delta z)+D \alpha z+D \epsilon
$$

Now since $m(\cdot)$ is assumed to be smooth function, the differencing removes the nonparametric effect as the $x_{i}$ come close. Hence, after removal of $m(\dot{)}$,

\footnotetext{
${ }^{20}$ See also Yatchew 1997, Hall, Kay and Titterington 1990.
} 
one is left with the equation

$$
D y \cong D \alpha z+D u
$$

which can be conviniently estimated by applying OLS. Yatchew (1997) shows that differencing in the context of partial linear models yields parameters which are

$$
\hat{\theta} \stackrel{a}{\sim}\left(\theta,\left(1+\frac{1}{2 j}\right) \frac{\sigma_{\epsilon}^{2}}{N V_{u}}\right)
$$

where $\sigma_{\epsilon}^{2}$ denotes the variance of the error term of model 21 .

The variance-covariance matrix of the estimated equivalence scales are recovered using the delta method (see Davidson and MacKinnon (2004)). Because the estimated parameters of the index model are

$$
n^{1 / 2}\left(\hat{\boldsymbol{\theta}}-\boldsymbol{\theta}_{0}\right) \stackrel{a}{\sim} N(\mathbf{0}, \boldsymbol{V})
$$

then for any monotone and continuously differentiable function $g(\cdot)$ that transforms the parameter vector $\boldsymbol{\theta}$ into the vector $\boldsymbol{\gamma}$, that is $\boldsymbol{\gamma}=g(\boldsymbol{\theta})$ one gets

$$
n^{1 / 2}\left(\hat{\gamma}-\gamma_{0}\right) \stackrel{a}{\sim} N\left(\mathbf{0}, \boldsymbol{G} \boldsymbol{V} \boldsymbol{G}^{\prime}\right)
$$

\section{A.2. Testing equality of the regression curves}

The test statistic for testing equality of regression curves is calculated as

$$
\Gamma=(m n)^{1 / 2}\left(s_{p}^{2}-s_{w}^{2}\right) /\left[s_{w}^{2}(2 \hat{\pi})^{1 / 2}\right] \sim N(0,1)
$$

where $s_{p}^{2}$ is the differencing estimator of the residual variance of the pooled data, $s_{w}^{2}$ is a weighted average of the residual variances of the two regression curves and $\hat{\pi}$ is $\operatorname{tr}(Q Q) / N T$, where $Q=P^{\prime} D^{\prime} D P-D^{\prime} D . P$ is a permutation matrix that reorders ascendingly the matrix to which it is applied and $D$ is the differencing matrix as defined above. $m$ and $n$ denote the order of differencing the number of observations in the pooled data respectively. See Yatchew (1999) for details. 